\title{
Cochrane
}

Library

Cochrane Database of Systematic Reviews

\section{Antipsychotic medication for childhood-onset schizophrenia} (Review)

Kennedy E, Kumar A, Datta SS

Kennedy E, Kumar A, Datta SS.

Antipsychotic medication for childhood-onset schizophrenia.

Cochrane Database of Systematic Reviews 2007, Issue 3. Art. No.: CD004027.

DOI: 10.1002/14651858.CD004027.pub2.

www.cochranelibrary.com 
TABLE OF CONTENTS

HEADER 1

ABSTRACT

PLAIN LANGUAGE SUMMARY

BACKGROUND

OBJECTIVES

METHODS

RESULTS

DISCUSSION

AUTHORS' CONCLUSIONS

ACKNOWLEDGEMENTS

REFERENCES

CHARACTERISTICS OF STUDIES

DATA AND ANALYSES

Analysis 1.1. Comparison 1 ATYPICAL vs TYPICAL ANTIPSYCHOTICS (only short term), Outcome 1 Global state: 1 . Worse or no improvement (CGI).

Analysis 1.2. Comparison 1 ATYPICAL vs TYPICAL ANTIPSYCHOTICS (only short term), Outcome 2 Global state: 2 . Mean end point score (Children Global Assessment Scale, high score=good).

Analysis 1.3. Comparison 1 ATYPICAL vs TYPICAL ANTIPSYCHOTICS (only short term), Outcome 3 Mental state: 1 . No improvement (BPRS).

Analysis 1.4. Comparison 1 ATYPICAL vs TYPICAL ANTIPSYCHOTICS (only short term), Outcome 4 Mental state: 2 . Mean end point score (BPRS, high score $=$ poor).

Analysis 1.5. Comparison 1 ATYPICAL vs TYPICAL ANTIPSYCHOTICS (only short term), Outcome 5 Mental state: 3 . Mean end point score (SANS, data skewed, high score = poor).

Analysis 1.6. Comparison 1 ATYPICAL vs TYPICAL ANTIPSYCHOTICS (only short term), Outcome 6 Mental state: 4 . Mean end point score (SAPS, data skewed, high score = poor).

Analysis 1.7. Comparison 1 ATYPICAL vs TYPICAL ANTIPSYCHOTICS (only short term), Outcome 7 Mental state: 5 . Mean end point score (The Bunny-Hamburg Psychosis Rating Scale, high score=poor).

Analysis 1.8. Comparison 1 ATYPICAL vs TYPICAL ANTIPSYCHOTICS (only short term), Outcome 8 Adverse effects: 1 . All adverse efects (TESS).

Analysis 1.9. Comparison 1 ATYPICAL vs TYPICAL ANTIPSYCHOTICS (only short term), Outcome 9 Adverse effects: $2 a$. Extrapyramidal adverse effects (TESS).

Analysis 1.10. Comparison 1 ATYPICAL vs TYPICAL ANTIPSYCHOTICS (only short term), Outcome 10 Adverse effects: $2 b$. Extrapyramidal average score (end point, high score = poor).

Analysis 1.11. Comparison 1 ATYPICAL vs TYPICAL ANTIPSYCHOTICS (only short term), Outcome 11 Adverse effects: 3. Somnolence/drowsiness (TESS).

Analysis 1.12. Comparison 1 ATYPICAL vs TYPICAL ANTIPSYCHOTICS (only short term), Outcome 12 Adverse effects: 4. Anticholinergic adverse effects (TESS).

Analysis 1.13. Comparison 1 ATYPICAL vs TYPICAL ANTIPSYCHOTICS (only short term), Outcome 13 Adverse effects: 5. Hypersalivation (TESS).

Analysis 1.14. Comparison 1 ATYPICAL vs TYPICAL ANTIPSYCHOTICS (only short term), Outcome 14 Adverse effects: 6 . Drop in the absolute neutrophil count below $1500 \mathrm{~mm}$ cube.

Analysis 1.15. Comparison 1 ATYPICAL vs TYPICAL ANTIPSYCHOTICS (only short term), Outcome 15 Adverse effects: 7. Seizure. .

Analysis 1.16. Comparison 1 ATYPICAL vs TYPICAL ANTIPSYCHOTICS (only short term), Outcome 16 Leaving the study early: 1. Due to adverse effects.

Analysis 1.17. Comparison 1 ATYPICAL vs TYPICAL ANTIPSYCHOTICS (only short term), Outcome 17 Leaving the study early: 2. Due to neuroleptic malignant syndrome.

Analysis 1.18. Comparison 1 ATYPICAL vs TYPICAL ANTIPSYCHOTICS (only short term), Outcome 18 Leaving the study early: 3. Due to drop in neutrophil count.

Analysis 2.1. Comparison 2 ATYPICAL vs ATYPICAL ANTIPSYCHOTICS (only short term), Outcome 1 Global state: 1. Not showing any response (CGI-S).

Analysis 2.2. Comparison 2 ATYPICAL vs ATYPICAL ANTIPSYCHOTICS (only short term), Outcome 2 Global state: 2 . Worsening of symptoms (CGI-S).

Analysis 2.3. Comparison 2 ATYPICAL vs ATYPICAL ANTIPSYCHOTICS (only short term), Outcome 3 Adverse effects: 1. Anticholinergic adverse effects. 
Analysis 2.4. Comparison 2 ATYPICAL vs ATYPICAL ANTIPSYCHOTICS (only short term), Outcome 4 Adverse effects: 2. Hypersalivation.

Analysis 2.5. Comparison 2 ATYPICAL vs ATYPICAL ANTIPSYCHOTICS (only short term), Outcome 5 Adverse effects: 4. Difficulty concentrating.

Analysis 2.6. Comparison 2 ATYPICAL vs ATYPICAL ANTIPSYCHOTICS (only short term), Outcome 6 Adverse effects: 5. Somnolence.

Analysis 2.7. Comparison 2 ATYPICAL vs ATYPICAL ANTIPSYCHOTICS (only short term), Outcome 7 Adverse effects: 7. Hypertension.

Analysis 2.8. Comparison 2 ATYPICAL vs ATYPICAL ANTIPSYCHOTICS (only short term), Outcome 8 Adverse effects: 1. Enuresis. . Analysis 2.9. Comparison 2 ATYPICAL vs ATYPICAL ANTIPSYCHOTICS (only short term), Outcome 9 Adverse effects: 10. Drop in absolute neutrophil count below 1500 cells/microlitre.

Analysis 2.10. Comparison 2 ATYPICAL vs ATYPICAL ANTIPSYCHOTICS (only short term), Outcome 10 Leaving the study early due to rapid deterioration in mental state.

Analysis 3.1. Comparison 3 TYPICAL vs TYPICAL ANTIPSYCHOTICS (only short term), Outcome 1 Global state: Unchanged or worse (CGI).

Analysis 3.2. Comparison 3 TYPICAL vs TYPICAL ANTIPSYCHOTICS (only short term), Outcome 2 Adverse effects: 1. All adverse effects (TESS).

Analysis 3.3. Comparison 3 TYPICAL vs TYPICAL ANTIPSYCHOTICS (only short term), Outcome 3 Adverse effects: 2. Extrapyramidal adverse effects (TESS).

Analysis 3.4. Comparison 3 TYPICAL vs TYPICAL ANTIPSYCHOTICS (only short term), Outcome 4 Adverse effects: 3 . Weight gain (TESS).

ADDITIONAL TABLES

WHAT'S NEW

HISTORY

CONTRIBUTIONS OF AUTHORS

DECLARATIONS OF INTEREST

SOURCES OF SUPPORT

INDEX TERMS 
[Intervention Review]

\section{Antipsychotic medication for childhood-onset schizophrenia}

Eilis Kennedy ${ }^{1}$, Ajit Kumar², Soumitra S Datta ${ }^{3}$

${ }^{1}$ Child and Family Department, Tavistock Clinic, London, UK. ${ }^{2}$ School of Medicine, University of Leeds, Leeds, UK. ${ }^{3}$ Department of Child and Adolescent Psychiatry PO85, Institute of Psychiatry, Kings College London, London, UK

Contact address: Eilis Kennedy, Child and Family Department, Tavistock Clinic, 120 Belsize Lane, Hampstead, London, NW3 5BA, UK. eiliskennedy@hotmail.com, ekennedy@tavi-port.nhs.uk.

Editorial group: Cochrane Schizophrenia Group

Publication status and date: Edited (no change to conclusions), published in Issue 6, 2012.

Citation: Kennedy E, Kumar A, Datta SS. Antipsychotic medication for childhood-onset schizophrenia. Cochrane Database of Systematic Reviews 2007, Issue 3. Art. No.: CD004027. DOI: 10.1002/14651858.CD004027.pub2.

Copyright @ 2012 The Cochrane Collaboration. Published by John Wiley \& Sons, Ltd.

\section{A B S T R A C T}

\section{Background}

Childhood-onset schizophrenia is schizophrenia with onset prior to the age of 13 years. Although it is rare, people who suffer from schizophrenia at an early age appear to have a clinically severe form of the illness with poor long-term prognosis. Antipsychotic medication is one way of managing this rare but serious mental illness.

\section{Objectives}

To examine the effects of antipsychotic medication for childhood-onset schizophrenia.

\section{Search methods}

We searched the Cochrane Schizophrenia Group Trials Register (November 2006 and February 2007), inspected references of all identified studies for further trials and contacted relevant pharmaceutical companies and authors of trials for additional information.

\section{Selection criteria}

We included all randomised clinical trials involving children and young people with a diagnosis of childhood onset schizophrenia (i.e. with a diagnosis of schizophrenia before the age of 13) comparing any antipsychotic drug with another antipsychotic or placebo.

\section{Data collection and analysis}

We reliably selected, quality assessed and extracted data from trials. We excluded data where more than $50 \%$ of participants in any group were lost to follow up. For homogenous dichotomous data we calculated random effects, relative risk (RR) and its $95 \%$ confidence interval $(\mathrm{Cl})$ and, where appropriate, number needed to treat (NNT) on an intention-to-treat basis. For normal continuous data we calculated the weighted mean difference (WMD).

\section{Main results}

From a total of 2062 citations, we identified six relevant trials. We categorised trials into three comparisons: atypical versus typical, atypical versus atypical and typical versus typical antipsychotic drugs. The only comparison to find any differences between treatment groups was atypical versus typical antipsychotic drugs. A few results from one study favoured the atypical antipsychotic clozapine over haloperidol in treating treatment resistant childhood-onset schizophrenia ( $n=21$, WMD CGAS $17.00 \mathrm{Cl} 7.74$ to 26.26; $n=21$, WMD Bunney-Hamburg Psychosis Rating Scale $-3.60 \mathrm{Cl}-6.64$ to -0.56). Participants on clozapine, however, were three times more likely to have drowsiness (1 RCT, $\mathrm{n}=21$, RR $3.30 \mathrm{Cl} 1.23$ to $8.85, \mathrm{NNH} 2 \mathrm{Cl} 2$ to 17 ) and half of the children receiving clozapine had neutropenia (1 RCT, $\mathrm{n}=21, \mathrm{RR} 12, \mathrm{Cl} 0.75$ to192.86). 


\section{Authors' conclusions}

There are few relevant trials and, presently, there is little conclusive evidence regarding the effects of antipsychotic medication for those with early onset schizophrenia. Some benefits were identified in using the atypical antipsychotic clozapine compared with haloperidol but the benefits were offset by an increased risk of serious adverse effects. Larger, more robust, trials are required.

\section{PLAIN LANGUAGE SUMMARY}

\section{Antipsychotic medication for childhood-onset schizophrenia}

Schizophrenia is a serious mental illness which can cause hallucinations, fixed false beliefs (delusions) and/or apathy, slowing and less movement or thought. For the majority of people, its onset is in the late teens or early twenties. However, although rare, the illness can appear in childhood, where it is generally more severe and the long term prospects are poorer. Childhood-onset is defined in this case as the illness appearing before the age of 13 years.

This review looks at the use of antipsychotic medication for those whose schizophrenia developed in childhood. Six trials were found containing a total of 256 children and adolescents. They were carried out in the USA or China and all lasted less than 12 weeks. All studies compared one antipsychotic against another, with the older first generation (typical) being compared against each other, first generation compared to second generation (atypical) and second generation compared to other second generation drugs. Two of the trials (46 children) compared these medications in participants for whom at least two other antipsychotics had not worked (treatment resistant schizophrenia).

It is difficult to draw general conclusions from this group of trials as they compare outcomes for different drugs, range from the 1970 s to 2006 (during this time the diagnosis of childhood schizophrenia has changed) and mostly have only small numbers of participants. The data suggests that the atypical antipsychotic clozapine shows a better general outcome when compared to typical antipsychotics. However, this depended on how the children in the trial were rated. Those on clozapine were more likely to show the adverse effects of sleepiness, decreased white blood cell count (agranulocytosis) and increased heartbeat (tachycardia) when compared to those on haloperidol. In another trial it was shown that haloperidol is more likely to cause movement side effects than risperidone. When comparing typical with typical, and atypical with atypical antipsychotics, no medication showed a significant improvement over another for the outcomes reported.

Although childhood-onset schizophrenia is rare, a large trial over multiple sites, where outcomes are measured over months rather than weeks would help establish which antipsychotics are helpful for this group of people.

(Plain language summary prepared for this review by Janey Antoniou of RETHINK, UK www.rethink.org). 


\section{B A C K G R O U N D}

Childhood-onset schizophrenia is defined as schizophrenia with onset prior to the age of 13 (APA 1994). Schizophrenia in this age group is sometimes referred to as very early onset schizophrenia (VEOS) with the term early onset schizophrenia (EOS) used to describe schizophrenia between the ages of 13 and 17 (Werry 1992). The onset of schizophrenia in childhood is extremely rare. The prevalence is estimated to be 50 times less than the adult form of the disorder (Beitchman 1985). There is, however, a paucity of definitive epidemiological studies and the true prevalence is likely to be even less (Clark 1988, Gillberg 2001). Two studies investigating rates of childhood neuropsychiatric disorders in Sweden and North Dakota found the prevalence of childhood onset schizophrenia to be 1.6 per 100000 children and 1.9 per 100000 children respectively (Burd 1987, Gillberg 1984, Gillberg 1987).

It is now believed that schizophrenia with onset in childhood has strong similarities with the adult form of the disorder (AACAP 2001). Historically, continuity with the adult form of the illness has not always been recognised (Parry-Jones 2001) although as far back as the early 1900s there have been descriptions of the childhood form of the disorder (Kraeplin 1919, Bleuler 1911). Between the 1930 s and the early 1970s the concept of childhood schizophrenia was broadened to include a heterogeneous group of childhood disorders collectively viewed as the 'childhood psychoses'. In particular infantile autism was considered a form of childhood schizophrenia (Kanner 1943, Kanner 1949). In the 1970s studies challenged this 'unitary' concept of schizophrenia in childhood and helped distinguish childhood schizophrenia as a distinct diagnostic criteria (Kolvin 1971, Rutter 1967, Rutter 1972). Since this time, the same diagnostic criteria have been used to diagnose the illness in childhood as in adulthood.

The diagnosis of schizophrenia in childhood can be difficult. The rarity of the disorder diminishes the predictive value of any diagnostic criteria (Hollis 2001). There are also thought to be phenomenological differences. A certain level of cognitive development/maturity is believed to be required in order to manifest complex positive symptoms (e.g. delusions, hallucinations). As compared to adolescent or adult schizophrenia, delusions are less frequent, particularly in children under 10. Only about $50 \%$ of cases will exhibit delusions and these are likely to be less complex and non-systematised. Auditory hallucinations more commonly occur and are reported in around $80 \%$ of cases (Volkmar 2001). Again they tend to be less complex and reflect developmental concerns (Green 1992, Russell 1994). Hallucinations in childhood are more frequently described as being internally located, making it difficult to distinguish such experiences from inner speech or thoughts (Garralda 1984). The onset of the majority of cases of childhood schizophrenia is insidious rather than acute (Asarnow 1988, Kolvin 1971). Such developmental variations in the presentation and expression of the illness can lead to a number of diagnostic dilemmas and ambiguities in reaching a diagnosis and can therefore make it difficult to ascertain when the illness began (Asarnow 2004).

Childhood schizophrenia represents a more severe form of the disorder with a higher genetic loading and poorer long-term prognosis (Kumra 1998, Hollis 2001). While on average a lower IQ is associated with schizophrenia at any stage of life, this association appears stronger in childhood (Hollis 2000, Jacobsen
1998, Asarnow 1988). Children with schizophrenia also have higher rates of cytogenetic abnormalities and premorbid developmental impairments (Usiskin 1999, Hollis 1995). In one study, $70 \%$ of children with onset of schizophrenia before the age of 10 had significant language and motor impairments in infancy. A subgroup of these children also had autistic symptoms and met the criteria for pervasive developmental disorder prior to the onset of schizophrenia (Watkins 1988, Hollis 1995). Such developmental impairments are more common in children with onset of illness before age 13 than in those with adolescent onset.

It is recognised that a proportion of children will present with developmental difficulties and psychotic symptoms yet will not fulfil adult based diagnostic criteria for schizophrenia. The term 'multidimensionally impaired disorder' has been used to describe such children (Asarnow 2004). Children considered to have 'multidimensionally impaired disorder' experience brief psychotic symptoms, frequent periods of emotional instability disproportionate to precipitants, excessive age inappropriate fantasy and prominent attention and impulse control difficulties (McKenna 1994). These children meet the DSM-IV criteria for psychotic disorder NOS (Asarnow 2004). They are an important group to consider, as they appear to be as numerous as those with 'true' schizophrenia (Kumra 1998). A higher rate of schizophrenia among first-degree relatives and increased rates of cytogenetic abnormalities suggest that such children may lie on the schizophrenic continuum. Follow up studies to date however have not revealed progression to a full schizophrenic illness (Jacobsen 1998, Kumra 1998, Hollis 2001). It is important to distinguish this sub-group of children as their psychotic symptoms appear to improve over time and long term treatment with antipsychotic medication may be inappropriate (Asarnow 2004).

In this review our aim was to look at the evidence for the antipsychotic treatment of childhood-onset schizophrenia. Traditionally the pharmacological treatment of disorders in childhood is an under-researched area (Riddle 2001, Clark 1988). This is despite awareness of the potential for different pharmacological effects in children. Indeed although continuities have been established between childhood and adult depression, children have been shown to differ in their response to antidepressant medication (Hazell 1995, Hazell 2001). Differences in neuroreceptor sensitivities are postulated (Remschmidt 1995). Animal studies suggest that children may be more sensitive to the extrapyramidal adverse effects of antipsychotic drugs (Baldessarini 1995).

The low prevalence of schizophrenia in childhood makes it difficult to organise treatment studies. Many clinicians will have experience of only a handful of cases at most (Calderoni 2001). Specialist centres enable clarification of the diagnoses (often necessary as misdiagnosis by non specialists is common) and co-ordination of the numbers required to undertake such studies.

\section{O B JECTIVES}

To examine the effects of antipsychotic drugs for children under 13 years with schizophrenia in comparison with placebo, no treatment, or each other. 


\section{ME T HOD S}

\section{Criteria for considering studies for this review}

\section{Types of studies}

We included all relevant randomised controlled trials. Where a trial was described as 'double-blind' but it was implied that the study was randomised, we included these trials in a sensitivity analysis. If there was no substantive difference within primary outcomes (see types of outcome measures) when these 'implied randomisation' studies were added, then we included these in the final analysis. If there was a substantive difference, we utilised only clearly randomised trials and described the results of the sensitivity analysis in the text. We excluded quasi-randomised (such as those allocating by using alternate days of the week) studies.

\section{Types of participants}

We included children with a diagnosis of schizophrenia according to standard diagnostic criteria i.e. diagnosed using DSM-III (APA 1980), ICD-9 (WHO 1978) or more recent versions of these classification systems e.g. ICD-10 (WHO 1992) and DSM IV (APA 1994). Older studies not using standard diagnostic criteria were also included but we took into account the likely diagnostic heterogeneity of these studies. We excluded children diagnosed with 'multidimensionally impaired disorder'. For the purposes of this review, the participants needed to be less than 13 years old at the time diagnosis. We included studies with young people over the age of 13 only if their schizophrenic illness had onset in childhood.

\section{Types of interventions}

1. Typical or 'conventional' antipsychotic drugs*

Typical antipsychotic drugs are considered effective in relation to positive symptoms (i.e. delusions, hallucinations) but are thought to have a greater propensity to cause extrapyramidal adverse effects (i.e. parkinsonism, dystonia, akathisia). Unwanted extrapyramidal adverse effects are attributed to the preferential blockade of dopamine receptors (especially D2 receptors) and also to the use of higher than optimal dosing regimes (Waraich 2002).

These drugs were further subdivided into:

(a)Typical high potency antipsychotic drugs (e.g. Haloperidol);

(b)Typical moderate/low potency antipsychotic drugs (e.g. Chlorpromazine).

Higher potency drugs are associated with greater dopamine receptor antagonism and extrapyramidal adverse effects when compared to lower potency drugs. Lower potency drugs are associated with more pronounced sedative and cardiovascular adverse effects.

\section{Atypical antipsychotic drugs ${ }^{\star}$}

These drugs (e.g. Risperidone, Olanzapine, Clozapine) have a different receptor affinity pattern which is not mainly based on dopamine receptor antagonism. Compared to 'typical' antipsychotic drugs they have a higher 5-HT2/D2 (serotoninergic/ dopaminergic) binding ratio. As a group, these drugs are thought to be less likely to cause extrapyramidal adverse effects but more likely to cause adverse effects such as weight gain. One atypical antipsychotic, clozapine, requires careful monitoring because of the risk of agranulocytosis (identified by detecting a low/reduced white blood cell count).

\section{Placebo}

*The above categorisation of 'typical' vs. 'atypical' antipsychotic drugs is based on current thinking regarding the broad differences between these groups of drugs and may change as understanding of their pharmacology and clinical effects evolves.

\section{Types of outcome measures}

We grouped outcomes according to time periods: short term (up to three months), medium term (three months to one year) and long term (more than one year).

\section{Primary outcomes}

1. Service utilisation outcomes

1.1 Hospital admission

2. Clinical response

2.1 Clinically significant improvement in global state - as defined by each of the studies

2.2 Clinically significant improvement in mental state - as defined by each of the studies

3. Educational attainment

3.1 Ability to attend school

4. Extrapyramidal adverse effects

4.2 Clinically significant extrapyramidal adverse effects - as defined by each of the studies

5. Other adverse effects, general and specific

5.1 Body Mass Index

6. Social functioning

6.1 Clinically significant improvement in social functioning/ interaction with peers - as defined by each of the studies

\section{Secondary outcomes}

1. Death: suicide or natural causes

2. Leaving the study early

3. Service utilisation outcomes

3.1 Days in hospital

3.2 Change in hospital status

3.3 Time spent with professional carer

4. Clinical response

4.1 Average score/change in global state

4.2 Average score/change in mental state

4.3 Clinically significant improvement in positive symptoms - as defined by each of the studies

4.4 Average score/change in positive symptoms

4.5 Clinically significant improvement in negative symptoms- as defined by each of the studies

4.6 Average score/change in negative symptoms

5. Educational attainment

5.1 Clinically significant improvement in educational attainment as defined by each of the studies

5.2 Average score/change in educational attainment

6. Behaviour 
6.1 Clinically significant improvement in behaviour (e.g. aggressive behaviour, behaviour on the ward etc.) - as defined by each of the studies

6.2 Average score/change in behaviour

7. Extrapyramidal adverse effects

7.1 Incidence of use of antiparkinsonian drugs

7.2 Average score/change in extrapyramidal adverse effects

8. Other adverse effects, general and specific

8.1 Number of people dropping out due to adverse affects

8.2 Cardiac effects

8.3 Anticholinergic effects

8.4 Antihistamine effects

8.5 Prolactin related symptoms

9. Social functioning

9.1 Average score/change in social functioning

9.2 Clinically significant improvement in ability to play - as defined

by each of the studies

9.3 Average score/change in ability to play

10. Economic outcomes

10.1 For the family

10.2 For the hospital

11. Quality of life/ satisfaction with care for either recipients of care or carers

11.1 Significant change in quality of life/ satisfaction - as defined by each of the studies

11.2 Average score/change in quality of life/ satisfaction

12. Cognitive functioning.

\section{Search methods for identification of studies}

\section{Electronic searches}

We searched the Cochrane Schizophrenia Group Trials Register (November 2006 and February 2007) using the phrase:

[( ${ }^{*}$ child $^{*}$ or *adolescent ${ }^{*}$ in title, abstract, index terms of REFERENCE] or [(child) in participants of STUDY]\}

This register is compiled by systematic searches of major databases, hand searches and conference proceedings (see Group Module).

\section{Searching other resources}

1. Reference searching

We inspected the references of all identified studies for more studies.

\section{Personal contact}

We contacted the first author or corresponding author of included studies for more information regarding unpublished trials.

3. Drug companies

We contacted the manufacturers of relevant compounds for additional data.

\section{Data collection and analysis}

1. Selection of trials
We (AK, SSD, EK) independently inspected all citations of studies identified by searching. Where disagreement occurred we resolved this by discussion, or, when there was still doubt, we acquired the full article for further inspection. Once we obtained the full articles AK decided whether they met review criteria and this was checked by SSD and EK. We attempted to resolve disagreement by discussion but if doubt remained we placed the study on the list of those awaiting assessment pending acquisition of more information.

2. Assessment of methodological quality

We assessed the methodological quality of included trials in this review using the criteria described in the Cochrane Handbook (Higgins 2005) and the Jadad Scale (Jadad 1996). The former is based on the evidence of a strong relationship between allocation concealment and direction of effect (Schulz 1995). The categories are defined below:

A. Low risk of bias (adequate allocation concealment)

B. Moderate risk of bias (some doubt about the results)

C. High risk of bias (inadequate allocation concealment). For the purpose of the analysis in this review, trials were included if they met the Cochrane Handbook criteria A or B.

The Jadad Scale measures a wider range of factors that impact on the quality of a trial. The scale includes three items:

1. Was the study described as randomised?

2. Was the study described as double-blind?

3. Was there a description of withdrawals and drop outs?

Each item receives one point if the answer is positive. In addition, a point can be deducted if either the randomisation or the blinding/ masking procedures described are inadequate. For this review we used a cut-off of two points on the Jadad scale to check the assessment made by the Handbook criteria. However, the Jadad Scale was not used to exclude trials.

\section{Data collection}

We (AK, SSD and EK) independently extracted data from selected trials. When disputes arose we attempted to resolve these by discussion. When this was not possible and further information was necessary to resolve the dilemma, we did not enter data and added the trial to the list of those awaiting assessment.

\section{Data synthesis}

\subsection{Data types}

We assessed outcomes using continuous (for example changes on a behaviour scale), categorical (for example, one of three categories on a behaviour scale, such as 'little change', 'moderate change' or 'much change') or dichotomous (for example, either 'no important changes' or 'important changes' in a person's behaviour) measures. Currently RevMan does not support categorical data so we were unable to analysis this.

\subsection{Incomplete data}

We did not include trial outcomes if more than $40 \%$ of people were not reported in the final analysis.

\subsection{Dichotomous - yes/no - data}

We carried out an intention to treat analysis. On the condition that more than $60 \%$ of people completed the study, everyone allocated to the intervention were counted, whether they completed the follow up or not. It was assumed that those who dropped out had 
the negative outcome, with the exception of death. Where possible, efforts were made to convert outcome measures to dichotomous data. This can be done by identifying cut off points on rating scales and dividing participants accordingly into 'clinically improved' or 'not clinically improved'. If the authors of a study had used a predefined cut off point for determining clinical effectiveness this was used by the reviewers where appropriate. Otherwise it was generally assumed that if there had been a $50 \%$ reduction in a scalederived score, this could be considered as a clinically significant response. Similarly, a rating of 'at least much improved' according to the Clinical Global Impression Scale (Guy 1976) was considered as a clinically significant response.

The relative risk (RR) and its 95\% confidence interval ( $\mathrm{Cl}$ ) was calculated based on the random effects model, as this takes into account any differences between studies even if there is no statistically significant heterogeneity. It has been shown that RR is more intuitive (Boissel 1999) than odds ratios which tend to be interpreted as RR by clinicians (Deeks 2000). This misinterpretation then leads to an overestimate of the impression of the effect. We inspected data to see if an analysis using a fixed effects model made any substantive difference in outcomes that were not statistically significantly heterogeneous. When the overall results were significant we calculated the number needed to treat (NNT) and the number-needed-to-harm (NNH) as the inverse of the risk difference.

\subsection{Continuous data}

4.4.1 Normally distributed data: continuous data on clinical and social outcomes are often not normally distributed. To avoid the pitfall of applying parametric tests to non-parametric data, we applied the following standards to all data before inclusion: (a) standard deviations and means were reported in the paper or were obtainable from the authors; (b) when a scale started from the finite number zero, the standard deviation, when multiplied by two, was less than the mean (as otherwise the mean is unlikely to be an appropriate measure of the centre of the distribution, (Altman 1996); (c) if a scale started from a positive value (such as PANSS which can have values from 30 to 210) the calculation described above was modified to take the scale starting point into account. In these cases skew is present if $2 \mathrm{SD}>(\mathrm{S}-\mathrm{Smin})$, where $\mathrm{S}$ is the mean score and Smin is the minimum score. Endpoint scores on scales often have a finite start and end point and these rules can be applied to them. When continuous data are presented on a scale which includes a possibility of negative values (such as change on a scale), it is difficult to tell whether data are nonnormally distributed (skewed) or not. Skewed data from studies of less than 200 participants would have been entered in additional tables rather than into an analysis. Skewed data poses less of a problem when looking at means if the sample size is large and would have been entered into a synthesis.

For change data (endpoint minus baseline), the situation is even more problematic. In the absence of individual patient data it is impossible to know if data are skewed, though this is likely. After consulting the ALLSTAT electronic statistics mailing list, we presented change data in MetaView in order to summarise available information. In doing this, we assumed either that data were not skewed or that the analyses could cope with the unknown degree of skew. Without individual patient data it is impossible to test this assumption. Where both change and endpoint data were available for the same outcome category, we only presented endpoint data. We acknowledge that by doing this much of the published change data were excluded, but argue that endpoint data are more clinically relevant and that if change data were to be presented along with endpoint data, it would be given undeserved equal prominence. We are contacting authors of studies reporting only change data for endpoint figures. We reported on-normally distributed data in the 'other data types' tables.

4.4.2 Rating scales: A wide range of instruments are available to measure mental health outcomes. These instruments vary in quality and many are not valid, or even ad hoc. For outcome instruments some minimum standards have to be set. It has been shown that the use of rating scales which have not been described in a peer-reviewed journal (Marshall 2000) are associated with bias, therefore we excluded the results of such scales. Furthermore, we stipulated that the instrument should either be a self report or be completed by an independent rater or relative (not the therapist), and that the instrument could be considered a global assessment of an area of functioning. However, as it was expected that therapists would frequently also be the rater, we included such data but commented on the data as 'prone to bias'.

Whenever possible we took the opportunity to make direct comparisons between trials that used the same measurement instrument to quantify specific outcomes. Where continuous data were presented from different scales rating the same effect, we presented both sets of data and inspected the general direction of effect.

\subsubsection{Summary statistic}

For continuous outcomes we estimated a weighted mean difference (WMD) between groups, again based on the random effects model, as this takes into account any differences between studies even if there is no statistically significant heterogeneity.

\subsection{Cluster trials}

Studies increasingly employ 'cluster randomisation' (such as randomisation by clinician or practice) but analysis and pooling of clustered data poses problems. Firstly, authors often fail to account for intra class correlation in clustered studies, leading to a 'unit of analysis' error (Divine 1992) whereby $p$ values are spuriously low, confidence intervals unduly narrow and statistical significance overestimated. This causes type I errors (Bland 1997, Gulliford 1999).

Where clustering was not accounted for in primary studies, we presented the data in a table, with a $\left(^{*}\right)$ symbol to indicate the presence of a probable unit of analysis error. In subsequent versions of this review we will seek to contact first authors of studies to obtain intra-class correlation co-efficients of their clustered data and to adjust for this using accepted method (Gulliford 1999). Where clustering has been incorporated into the analysis of primary studies, we also presented these data as if from a non-cluster randomised study, but adjusted for the clustering effect.

We have sought statistical advice and have been advised that the binary data as presented in a report should be divided by a 'design effect'. This is calculated using the mean number of participants per cluster $(\mathrm{m})$ and the intraclass correlation co-efficient (ICC) [Design effect $=1+(m-1)^{\star} I C C$ (Donner 2002). If the ICC was not reported it was assumed to be 0.1 (Ukoumunne 1999). 
If cluster studies had been appropriately analysed taking into account intra-class correlation coefficients and relevant data documented in the report, synthesis with other studies would have been possible using the generic inverse variance technique.

\section{Investigation for heterogeneity}

Firstly, we considered all the included studies within any comparison to judge clinical heterogeneity. Then visual inspection of graphs was used to investigate the possibility of statistical heterogeneity. This was supplemented using, primarily, the Isquared statistic. This provides an estimate of the percentage of variability due to heterogeneity rather than chance alone. Where the I-squared estimate was greater than or equal to $75 \%$, we interpreted this as indicating the presence of high levels of heterogeneity (Higgins 2003). If inconsistency was high, we did not summate data, but presented the data separately and investigated the reasons for heterogeneity.

\section{Addressing publication bias}

We entered data from all identified and selected trials into a funnel graph (trial effect versus trial size) in an attempt to investigate the likelihood of overt publication bias.

\section{General}

Where possible, we entered data in such a way that the area to the left of the line of no effect indicated a favourable outcome for the trial antipsychotic.

\section{RES U L T S}

\section{Description of studies}

\section{Excluded studies}

We excluded 12 studies: three were not randomised (Fish 1966, Frazier 1994, Liang 2003) three studies did not include participants with a diagnosis of childhood onset schizophrenia (Gram 1972, Lewis 1972, Nagaraja 1977) one study did not have data specifically for those with a diagnosis of childhood onset schizophrenia (Claghorn 1972), two studies did not have any age specific data for the participants(McGlashan 2003, Sikich 2004) for one study there was no data available before crossover (Spencer 1996) and from another study ( Tandon 2005) there was no data available comparing groups. One study specifically recruited only adolescents (van Nimwegen 2006). We attempted to contact the authors of Tandon 2005 and Spencer 1996 but have not yet heard from them.

\section{Awaiting assessment}

One study, Magnuson 2001, awaits assessment as we have very few details on this trial.

\section{Ongoing studies}

We know of no ongoing studies.

\section{Included studies}

We identified six studies (eight reports) for inclusion (Faretra 1970, Kumra 1996, Shaw 2006, Xiong 2004, Yao 2003, Engelhardt 1973). All six studies were described as randomised. In two studies (Xiong 2004, Yao 2003) the blindness at outcome was unclear.

\subsection{Length of trials}

All studies reported data on short-term follow-up (up to 12 weeks). There was no trial reporting data on medium-term (13 to 26 weeks) or long-term follow-up (over 26 weeks).

\subsection{Participants}

In total 256 children and adolescents were involved in these trials. Two of these studies (Engelhardt 1973, Faretra 1970) did not use operationalised criteria to diagnose schizophrenia and these studies are therefore likely to be diagnostically heterogeneous. Two studies comparing the atypical antipsychotic clozapine (Shaw 2006, Kumra 1996) included children and young people with treatment resistant childhood onset schizophrenia defined as a failure to respond to or tolerate at least two different antipsychotic drugs. Overall there were more boys in these studies than girls (153 boys, 85 girls). One study, Yao 2003, did not specify the gender of some of the participants. The age range across the studies was between five and 18 years of age. Young people over the age of 13 included in the studies had been diagnosed with schizophrenia in childhood.

\subsection{Setting}

Four of the six studies were described as taking place in hospital or inpatient settings (Faretra 1970, Kumra 1996, Shaw 2006, Xiong 2004). Yao 2003 took place in both inpatient and outpatient settings and Engelhardt 1973 took place exclusively in the outpatient setting.

\subsection{Study size}

Three studies recruited 60 children and adolescents (Faretra 1970, Xiong 2004, Yao 2003). Kumra 1996, Shaw 2006 and Engelhardt 1973 involved between 21 and 30 children and adolescents.

\subsection{Interventions}

The trialists administered typical and atypical antipsychotic drugs in a wide range of doses. Daily dose ranges of typical antipsychotic drugs used as interventions were wide ranging (haloperidol 0.5-27 $\mathrm{mg}$, chlorpromazine $50-400 \mathrm{mg}$, fluphenazine $3.75-10.4 \mathrm{mg}$ ). The atypical antipsychotic drugs used were clozapine, risperidone and olanzapine (clozapine $25-525 \mathrm{mg}$, risperidone $0.25-5 \mathrm{mg}$, olanzapine 5-20mg).

\subsection{Outcomes}

Studies reported on global outcomes in several ways. Four trials used Clinical Global Impression scores (CGI; Guy 1976) scores to measure global clinical improvement in the short term (Engelhardt 1973, Faretra 1970, Kumra 1996, Shaw 2006). Kumra 1996 used the Children's Global Assessment Scale to assess global functioning (CGAS; Schaffer 1983).

Trials used several scales to measure mental state. Four studies (Kumra 1996, Shaw 2006, Xiong 2004, Yao 2003) reported outcome of mental state using the Brief Psychiatric Rating Scale (BPRS; Overall 1962). Kumra 1996 and Shaw 2006 also used the Scale for the Assessment of Negative Symptoms (SANS; Andreasen 1983) and the Scale for the Assessment of Positive Symptoms (SAPS; Andreasen 1984) to report outcome.

All studies reported usable data on adverse effects. Many studies used Treatment Emergent Symptoms Scale (TESS; Guy 1976) and the Abnormal Involuntary Movements Scale (AIMS;Guy 1976) to report adverse effects. Only one study (Engelhardt 1973) reported usable data on weight gain.

Kumra 1996 and Shaw 2006 reported the reasons for participants leaving the study early. 
4.6.1 Outcome scales: details of only the scales that provided usable data are shown below. Reasons for exclusions of data are given under 'Outcomes' in the 'Included studies' section.

\subsubsection{Global state}

4.6.1.1.1 Clinical Global Impression Scale - CGI Scale (Guy 1976)

Trialists used this to assess both severity of illness and clinical improvement. The CGI is a seven-point scoring system is usually used with low scores showing decreased severity and/or overall improvement.

\subsection{Childrens Global Assessment Scale (Schaffer 1983)}

The Childrens Global Assessment Scale (CGAS) is used to provide a global measure of level of functioning in children and adolescents. The measure provides a single global rating only, on scale of 0-100. In making their rating, the clinician makes use of the glossary details to determine the meaning of the points on the scale.

\subsubsection{Mental state scales}

\subsection{Brief Psychiatric Rating Scale - BPRS (Overall 1962)}

This is used to assess the severity of abnormal mental state. The original scale has 16 items, but a revised 18 -item scale is commonly used. Each item is defined on a seven-point scale varying from 'not present' to 'extremely severe', scoring from 0-6 or 1-7. Scores can range from $0-126$, with high scores indicating more severe symptoms.

4.6.1.2.2 Comprehensive Psychopathological Rating Scale - CPRS (Montgomery 1979)

This is an extension subscale for schizophrenia which contains 16 items. High score indicates more severe symptoms.

4.6.1.2.3 Positive and Negative Syndrome Scale - PANSS (Kay 1987) This schizophrenia scale has 30 items, each of which can be defined on a seven-point scoring system varying from 1 - absent to 7 - extreme. This scale can be divided into three sub-scales for measuring the severity of general psychopathology, positive symptoms (PANSS-P), and negative symptoms (PANSS-N). A low score indicates lesser severity.

4.6.1.2.4 Bunney-Hamburg Psychosis Rating Scale (Bunney 1963) The Bunney-Hamburg Psychosis Rating Scale is a 15 point scale that provides a clinical rating of severity of psychosis ranging from no symptoms to incapacitating symptoms. Scores range from 1 , no symptoms of psychosis, to 15 , incapacitating symptoms of psychosis.

\subsubsection{Adverse effects scales}

4.6.1.3.1 Treatment Emergent Symptoms Scale - TESS (Guy 1976) This checklist assesses a variety of characteristics for each adverse event including: severity, relationship to the drug; temporal characteristics (timing after a dose, duration and pattern during the day); contributing factors; course and action taken to counteract the effect. Symptoms can be listed a priori or can be recorded as observed by the investigator.

\subsection{Simpson Angus Scale (Simpson 1970)}

Simpson-Angus Scale (SAS) is a 10-item rating scale that has been used widely for assessment of neuroleptic medication induced movement disorders in research settings. It consists of one item measuring gait (hypokinesia), six items measuring rigidity and three items measuring glabella tap, tremor and salivation, respectively.
4.6.1.3.3 Abnormal Involuntary Movements Scale (Guy 1976)

This is a 12 item scale each item scored on a 0 to 4 . It is used to monitor antipsychotic medication induced movement disorders. It has separate items for oral and facial movements, movement of extremities, trunk and global judgements.

\subsubsection{Redundant data}

Enormous efforts were invested in studies, rating and recording data that are poorly reported and therefore unusable. Trialists often report continuous measures of global, or mental state, or adverse effects but fail to report variances.

\subsubsection{Missing outcomes}

We found no usable outcomes for the following categories: education attainment, behaviour, social outcome and service outcomes. It is possible that there is a systematic bias in which data, such as the simple binary outcome of death, are not reported consistently or well.

\subsubsection{Primary outcomes}

None of the studies reported our pre-stated primary outcome of relapse. At the time of writing the protocol, all other outcomes in this review were felt to be of secondary importance but we recognise that they may be of primary interest to others.

\section{Risk of bias in included studies}

\section{Randomisation}

All studies included in the review were reported to be randomised, but most of the included studies did not explicitly describe the method by which this was done. With this poor reporting of how randomisation sequences were kept concealed it is likely that the studies are prone to at least a moderate degree of bias and we categorised the majority of studies as 'B' (see Methods 2). Only Shaw 2006 described the in detail the method of randomisation, giving details of allocation concealment, it was therefore categorised as an 'A' grade methodological study, with a low risk of bias.

\section{Blinding}

Again, the majority of the studies reported that they were double blind, however, little detail was given regarding the formal assessment of adherence to blinding. Xiong 2004 and Yao 2003 did not report clearly whether the study was double blind.

\section{Leaving the study early}

Reasons for leaving the study early were only reported in two studies. We have reported these in the outcomes.

\section{Data reporting}

Overall, due to poor reporting, we were unable to use a lot of the data. Findings presented as graphs, whether as percentiles or as inexact p-values, are often of little use to a reviewer. Some studies failed to provide standard deviations when reporting mean changes. We are seeking further data from the first authors of relevant trials.

\section{Effects of interventions}

\section{The search}

We identified a total of 2062 citations using the search strategy. Following this systematic search for controlled clinical trials we found only six studies (total $n=256$ ) fulfilling our inclusion criteria 
(Engelhardt 1973, Faretra 1970, Kumra 1996, Shaw 2006, Xiong 2004, Yao 2003).

\section{COMPARISON 01: ATYPICAL versus TYPICAL ANTIPSYCHOTIC DRUGS (only short term)}

This comparison included three studies (total $n=141$ ).

\subsection{Global state}

Only Kumra 1996 reported data on global state and reported it in both binary and continuous forms. For the outcome of 'worse or no improvement' as measured by the Clinical Global Impression Scale (CGI; Guy 1976) no clear difference was found, although confidence intervals were wide $(1 \mathrm{RCT}, \mathrm{n}=21, \mathrm{RR} 3.30 \mathrm{Cl} 0.41$ to 26.81). However global functioning, as assessed by the Children's Global Assessment Scale (CGAS;Schaffer 1983) did show a clear difference in favour of clozapine (1RCT $n=21$, WMD $17.00 \mathrm{Cl} 7.74$ to 26.26).

\subsection{Mental state}

Three studies reported mental state (Kumra 1996, Yao 2003, Xiong 2004). The scales used were the Brief Psychiatric Rating Scale, Scale for the Assessment of Negative Symptoms, Positive and Negative Syndrome Scale and Bunney-Hamburg Psychosis Rating Scale. We have one dichotomous outcome reported by Xiong 2004 as 'no improvement'. Data do not show any statistically significant difference between risperidone and chlorpromazine ( $1 \mathrm{RCT}, \mathrm{n}=60$, RR $1.2 \mathrm{Cl} 0.41$ to 3.51). All three studies gave the mean end point score of the Brief Psychiatric Rating Scale. Results show a trend favouring atypical antipsychotic drugs over typical antipsychotic drugs but the result just fails to reach statistical significance ( 3 RCTs, $n=123$, WMD $-1.71, \mathrm{Cl}-3.51$ to 0.10 ). Kumra 1996 reported mean end point scores on the Scale for the Assessment of Negative Symptoms. Skewed data favoured clozapine over haloperidol. The same study again favoured clozapine over haloperidol for data from the Bunney-Hamburg Psychosis Rating Scale (1 RCT, n=21, WMD $-3.60 \mathrm{Cl}-6.64$ to -0.56$)$.

\subsection{Adverse effects}

Yao 2003 used the Treatment Emergent Symptoms Scale (TESS; Guy 1976) to report all adverse effects and data showed that participants treated with risperidone tend to have less adverse effects, compared to haloperidol ( $1 \mathrm{RCT}, \mathrm{n}=42$, RR $0.48 \mathrm{Cl} 0.30$ to 0.75 , NNT $2 \mathrm{Cl} 2$ to 5). Extrapyramidal adverse effects reported by the same study again favours risperidone over haloperidol (1 RCT, n=42, RR $0.10 \mathrm{Cl} 0.03$ to 0.36 , NNT $2 \mathrm{Cl} 2$ to 2). Kumra 1996 reported that participants on clozapine were three times more likely to have drowsiness as an adverse effect as compared to haloperidol ( $1 \mathrm{RCT}, \mathrm{n}=21$, RR $3.30 \mathrm{Cl} 1.23$ to 8.85 , NNH $2 \mathrm{Cl}$ 2 to 17). While not reaching statistical significance, half of the participants (five out of 10) on clozapine in Kumra 1996 had a drop in absolute neutrophil count below $1500 \mathrm{~mm} 3$ and none of the participants on haloperidol experienced this adverse effect (1 $\mathrm{RCT}, \mathrm{n}=21, \mathrm{RR} 12, \mathrm{Cl} 0.75$ to192.86). Typical antipsychotic drugs are consistently associated with more anticholinergic adverse effects like dizziness and dry mouth. But the statistical significance of this in the analyses seems to be affected by inclusion of a particular study Yao 2003, which used haloperidol as the comparator arm. The study comparing risperidone versus chlorpromazine (Xiong 2004) did not find a significant difference in the anticholinergic adverse effects as dizziness and dry mouth.
Only Kumra 1996 reported in sufficient details the reason for leaving the study early due to adverse effects. Three participants out of ten taking clozapine needed to be withdrawn from the study early because of serious adverse effects compared to one participant taking haloperidol. There was no statistically significant difference between the clozapine and haloperidol group for attrition due to adverse effects ( $1 \mathrm{RCT}, \mathrm{n}=21, \mathrm{RR} 3.30 \mathrm{Cl} 0.41$ to 26.81), neuroleptic malignant syndrome ( $1 \mathrm{RCT}, \mathrm{n}=21, \mathrm{RR} 0.36 \mathrm{Cl} 0.02$ to 8.03), drop in neutrophil count ( $1 \mathrm{RCT}, \mathrm{n}=21, \mathrm{RR} 5.45 \mathrm{Cl} 0.29$ to 101.55 ) or seizures (1 RCT, n=21, RR $5.45 \mathrm{Cl} 0.29$ to 101.55).

3. COMPARISON: 2. ATYPICAL versus ATYPICAL ANTIPSYCHOTIC DRUGS (only short term)

This comparison included only one study (total $n=25$ ).

3.1 Global state

Shaw 2006 reported data on global state. It failed to show any statistically significant difference between clozapine and olanzapine for 'not showing any response' ( $1 \mathrm{RCT}, \mathrm{n}=25, \mathrm{RR} 1.35 \mathrm{Cl}$ 0.47 to 3.89 ) and 'worsening of symptoms' ( $1 \mathrm{RCT}, \mathrm{n}=25, \mathrm{RR} 0.22 \mathrm{Cl}$ 0.01 to 4.08$)$.

\subsection{Adverse effects}

As regards anticholinergic adverse effects, Shaw 2006 found no differences between groups for constipation ( $1 \mathrm{RCT}, \mathrm{n}=25$, RR 1.08 $\mathrm{Cl} 0.18$ to 6.53) or ECG anomalies ( $1 \mathrm{RCT}, \mathrm{n}=25$, RR $2.17 \mathrm{Cl} 0.22$ to 20.94) but reported three times more incidence of tachycardia with clozapine as compared with olanzapine (1 RCT, $n=25, R R 3.25$, $\mathrm{Cl} 1.14$ to 9.24 , NNH $2 \mathrm{Cl} 2$ to 32 ). There were also no significant difference between groups for the adverse effects of somnolence ( $\mathrm{n}=25,1 \mathrm{RCT}, \mathrm{RR} 1.08, \mathrm{Cl} 0.18$ to 6.53 ), difficulty concentrating (1 $R C T, n=25, R R 4.33 \mathrm{Cl} 0.56$ to 33.53), enuresis (1 RCT, $n=25$, RR 5.42 $\mathrm{Cl} 0.73$ to 39.97) or drop in neutrophil count (1 RCT, $n=25$, RR 2.17 $\mathrm{Cl} 0.22$ to 20.94). Interestingly more children in the clozapine group had hypertension, although the finding did not reach statistical significance (1 RCT, $\mathrm{n}=25$, RR 2.89, $\mathrm{Cl} 0.99$ to 8.42 ).

3.3 Leaving the study early

Shaw 2006 reported one child among thirteen left the study early due to rapid deterioration in mental state in the olanzapine group, the difference between the two treatment groups, however, was not significant (1 RCT, $\mathrm{n}=25$, RR $0.36 \mathrm{Cl} 0.02$ to 8.05 ).

\section{COMPARISON 3. TYPICAL versUS TYPICAL ANTIPSYCHOTIC DRUGS} (only short term)

This comparison included two studies (Engelhardt 1973 and Faretra 1970) (total $n=90)$.

\subsection{Global state}

The global state was reported as unchanged or worse by Faretra 1970. The data reported showed no difference between fluphenazine and haloperidol for anxiety $(1 \mathrm{RCT}, \mathrm{n}=60, \mathrm{RR} 0.86 \mathrm{Cl}$ 0.48 to 1.53 ) or regressive behaviour ( $1 \mathrm{RCT}, \mathrm{n}=60$, RR $0.92 \mathrm{Cl} 0.69$ to 1.21$)$.

\subsection{Adverse effects}

Both fluphenazine and haloperidol did not show a statistically significant difference as regards to overall incidence of extrapyramidal adverse effects ( $n=902$ RCTs, RR $1.20, \mathrm{Cl} 0.58$ to 2.46) or weight gain ( $1 \mathrm{RCT}, \mathrm{n}=30$, RR $0.86 \mathrm{Cl} 0.64$ to 1.14 ).

\subsection{Leaving the study early}




\section{DISCUSSION}

\section{Few studies}

The low prevalence of childhood onset schizophrenia makes it difficult to study. This may be one of the reasons for the scarcity of controlled clinical trials. Half of the six studies identified had less than 30 participants in total and none of the studies had more than 60 . The relative rarity of the illness combined with challenges in ascertaining a diagnosis in this age group make it likely that treatment studies for this disorder will be costly and require multiple sites and extensive efforts to find eligible participants.

\subsection{Applicability of findings}

The included studies were conducted either in the USA or China. While some of the trials exclusively included children below the age of 13 , other studies included, in addition, adolescents whose schizophrenic illness had been diagnosed in childhood. Two studies using the atypical antipsychotic clozapine included participants whose illness had proved resistant to treatment with at least two previous antipsychotic drugs (Shaw 2006, Kumra 1996). Two studies conducted in the early 1970s are likely to have been undertaken with a diagnostically heterogeneous group as in the past, autism and childhood schizophrenia were not clearly distinguished (Faretra 1970, Engelhardt 1973). Only two studies did not specifically exclude those with a learning disability (Yao 2003, Faretra 1970).

\subsection{Limited data}

The collection and quality of the data reported was very variable. All included studies reported data only for the short term (less than 12 weeks). To further undermine the value of the studies, many reported mean figures without giving the standard deviation and therefore these averages were meaningless. Among the 12 groups of pre-defined outcomes, only five were addressed by the studies. We found no data on educational attainment, social outcome, service outcomes, satisfaction with treatment or economic outcomes. Outcomes were commonly reported using graphs and $\mathrm{p}$-values instead of tables and confidence intervals. The excessive use of graphs did not allow us to acquire sufficient numbers to calculate many measures of effects.

\subsection{Quality of studies}

We appreciate that studies in this population group bring unique difficulties. There were, however, important methodological difficulties with the trials and therefore any conclusions must be viewed with caution. There is a danger of inclusion of at least a moderate risk of bias in these results (Higgins 2005). Selection bias can be minimised through good quality blinding at allocation. Improper allocation concealment can affect estimation of treatment effects (Chalmers 1983). Only Shaw 2006 gave a good description of allocation concealment.

\section{COMPARISON 1. ATYPICAL ANTIPSYCHOTIC DRUGS VS TYPICAL ANTIPSYCHOTIC DRUGS (only short term)}

We included three trials published after 1996 comparing a typical antipsychotic with an atypical antipsychotic for children with schizophrenia (Kumra 1996, Yao 2003, Xiong 2004). Only Kumra 1996 reported on global outcomes. Scale data from the Children's Global Assessment Scale (CGAS; Schaffer 1983) did favour the atypical clozapine over haloperidol (1 RCT, n=21, WMD $17.00 \mathrm{Cl}$ 7.74 to 26.26) and such a shift on the CGAS is likely to be clinically significant. The same study again favoured clozapine over haloperidol for data from the Bunney-Hamburg Psychosis Rating Scale (1 RCT, n=21, WMD $-3.60 \mathrm{Cl}-6.64$ to -0.56). Kumra 1996 focused on a group with treatment resistant schizophrenia, defined as a failure to tolerate or respond to two different antipsychotic medications. It appears from the baseline assessment scores that the participants in this study had a severe form of illness - the study authors report that the level of baseline psychopathology characteristics was higher than that previously reported for adult inpatients in studies of clozapine e.g. Kane 1988. It is perhaps not surprising given the known benefits of clozapine for adults with treatment resistant schizophrenia that clozapine did offer some advantage in improving mental state and global functioning in this group when compared to the typical antipsychotic haloperidol. However these findings may not be generalisable to all children with childhood-onset schizophrenia who may or may not have a treatment resistant form of the illness. The benefits of clozapine in this study also need to be balanced against the considerable risk of adverse effects. Those treated with clozapine were three times more likely to have drowsiness as an adverse effect as compared to haloperidol and five out of the10 participants taking clozapine had a significant drop in neutrophil count compared to none of the participants taking haloperidol ( $1 \mathrm{RCT}, \mathrm{n}=21, \mathrm{RR} 12, \mathrm{Cl} 0.75$ to 192.86). Three participants out of 10 taking clozapine needed to be withdrawn from the study early because of serious adverse effects compared to one participant taking haloperidol. The risk of agranulocytosis with clozapine treatment may be greater in those below the age of 21 and therefore should be particularly carefully monitored in this age group (Alvir 1993).

On continuous measures such as the mean end point scores on the BPRS, none of the atypical antipsychotic medications were found to be superior to the typical antipsychotic agents (Xiong 2004, Yao 2003, Kumra 1996). There was no difference in outcome if an atypical antipsychotic drug was compared with a low potency typical antipsychotic such as chlorpromazine in a group not selected for treatment resistant schizophrenia (Xiong 2004).

3. COMPARISON 2. ATYPICAL vS ATYPICAL ANTIPSYCHOTIC DRUGS (only short term)

There was only one study comparing clozapine with olanzapine (Shaw 2006). The participants in this study had a diagnosis of treatment resistant schizophrenia (as shown by a failure to respond to at least two antipsychotic drugs). The study failed to show any superiority of clozapine over olanzapine. This is not in keeping with the available evidence for adults with schizophrenia. Moreover there were some adverse effects such as tachycardia and hypertension reported more often by children with schizophrenia on clozapine. The lack of a better response could be due to small sample size $(n=25)$ and could very well be due to a type II error. Studies with a larger sample size would examine with greater clarity the effectiveness of clozapine as compared to other atypical antipsychotics for this age group. The longer term adverse effects of using olanzapine and clozapine in this age group need to be investigated systematically. The advantage/disadvantage of use of one atypical antipsychotic over another should be subject to further research.

\section{COMPARISON 3. TYPICAL VS TYPICAL ANTIPSYCHOTIC DRUGS (only short term)}

We found two studies undertaken in the early 1970s comparing fluphenazine with haloperidol (Engelhardt 1973 and Faretra 1970). 
The diagnosis of childhood onset schizophrenia in these studies is less certain. No differences between the two drugs were identified with regard to the outcomes assessed. With the advent of many newer medications, typical antipsychotic medications have become somewhat unpopular with researchers and clinicians. Given that some of the recent studies (Xiong 2004) found very little difference between risperidone and chlorpromazine for childhoodonset schizophrenia, these agents should probably be investigated further. In lower doses the pharmacodynamics of chlorpromazine has similarity with many of the newer atypical antipsychotic medications.

\section{AUTHORS' CONCLUSIONS}

\section{Implications for practice}

1. For children/young people with schizophrenia and their families/ carers.

With the current available evidence, there is some suggestion that childhood-onset schizophrenia improves with treatment with antipsychotic medications. There are very few well designed trials and not much data are available for us to conclude that any one drug is better than another or that the newer drugs are significantly better than the older ones. This evidence, however, is drawn from a small sample of few studies and we cannot be confident that it will still be evident in larger more robust studies. For children and adolescents who have not responded to other medications, clozapine is a good alternative and appears to have some benefits in the treatment of psychotic symptoms and improving general functioning; however this is at the expense of an increased risk of adverse effects. While the focus of the current review is on the role of antipsychotic medications in the treatment of childhood-onset schizophrenia, it is important to point out that other interventions such as psychoeducation, better understanding about the illness by family members and psychological therapies are likely to be complementary.

\section{For clinicians}

As yet there are few data to support the use of one antipsychotic medication over another in the treatment of schizophrenia with onset in childhood. This finding is likely to change with larger more robust trials. There is some evidence that clozapine is superior to haloperidol for children and young people with treatment resistant schizophrenia, but the use of clozapine is associated with a considerable increased risk of adverse effects (Kumra 1996). This superiority of atypical antipsychotic medications over typical antipsychotic drugs is not reflected in studies using other typical medications like chlorpromazine as the comparator medication, instead of haloperidol and where the participants do not have a treatment resistant form of the illness (Xiong 2004).

\section{For managers/policy makers}

Antipsychotic medications should be available as a treatment option for children and young people with childhood onset schizophrenia. As there is lack of robust evidence, it would be ideal to have local protocols to monitor response and adverse effects on a regular and ongoing basis.

\section{Implications for research}

1. General

If the recommendations of the CONSORT statement (Moher 2001) had been anticipated by trialists much more data would have been available. Allocation concealment is essential for the result of a trial to be considered valid and gives the assurance that selection bias is kept to the minimum. Well-described and tested blinding could have encouraged confidence in the control of performance and detection bias. It is also important to know how many, and from which groups, people were withdrawn, in order to evaluate exclusion bias. It would have been helpful if authors had presented data in a useful manner which reflects association between intervention and outcome, for example, relative risk, odds-ratio, risk or mean differences, as well as raw numbers. Binary outcomes should be calculated in preference to continuous results, as they are easier to interpret. If $\mathrm{p}$-values are used, the exact value should be reported.

\section{Specific}

There is little evidence supporting the effectiveness of antipsychotic medication in the treatment of childhood-onset schizophrenia. There is no significant increase in the number of trials in the last three decades probably reflecting the challenges of undertaking research with this age group. We do think that more trials are indicated. These should not only be large and long but should also adhere to a pragmatic design in order to increase applicability. Methods should be rigorous and involve good concealment of allocation and follow up. Participants should be children and young people recognisable in everyday life and not those who are so strictly diagnosed as to render them unrecognisable to routine care. Comparing interventions should involve standard doses of antipsychotic drugs that are real choices in the region of the study. Outcomes should be measured over months rather than weeks as this is the usual period a child or young person would be recommended to take the medication. Long term follow up will be especially important as the poor prognosis of the childhood form of schizophrenia will mean that many children will require treatment over a long period of time. We suggest that if scales are to be used, validated and clinically meaningful outcomes are pre-defined. Routine outcomes such as relapse, educational attainment, social functioning, satisfaction with care, serious or troubling adverse effects can all be easily recorded without the use of scales and we would suggest that these are included in the design of the study. Given the relative rarity of childhood onset schizophrenia, future treatment studies will require multi-centre collaboration and extensive case finding efforts. See also Table 1.

\section{ACK N OWLEDGEMENTS}

We would like to thank Judith Wright, Trials Search Co-coordinator, CSG, for undertaking all the searches for the current review, Tessa Grant for her warm and enthusiastic administrative support, Jun Xia for translating the included Chinese studies, Yorkshire Deanery and North West Deanery, UK for funding of SSD for research one day per week and Professor Clive Adams, Editor of CSG for his guidance at all stages of the review. We also thank Dr. Ana Paola Robatto Nunes for being a co-author in developing the original protocol. 


\section{RE F E R E N C E S}

\section{References to studies included in this review}

Engelhardt 1973 \{published data only\}

Engelhardt DM, Polizos P, Waizer J, Hoffman SP. A double blind comparison of fluphenazine and haloperidol in outpatient schizophrenic children. Journal of Autism and Childhood Schizophrenia 1973;3(2):128-37. [PsycINFO 52-03645]

\section{Faretra 1970 \{published data only\}}

Faretra G, Dooher L, Dowling J. Comparison of haloperidol and fluphenazine in disturbed children. American Journal of Psychiatry 1970;126:1670-3. [MEDLINE: 5443653]

\section{Kumra 1996 \{published data only\}}

Huffman GB. Efficacy of clozapine for schizophrenia in children. American Family Physician 1997;55(4):1356. [MEDLINE: 8936902]

Kumra S, Frazier JA, Jacobsen LK, McKenna K, Gordon CT, Lenane MC, Hamburger SD, Smith AK, Albus KE, Alaghband Rad J, Rapoport JL. Childhood-onset schizophrenia. A doubleblind clozapine-haloperidol comparison. Archives of General Psychiatry 1996;53(12):1090-7. [MEDLINE: 97115273; 8956674]

Kumra S, Jacobsen LK, Rapoport JL. Childhood-onset schizophrenia - a double-blind clozapine trial. 149th Annual Meeting of the American Psychiatric Association; 1996 Oct 4 May 9; New York, USA. 1996. [MEDLINE: 97115273]

\section{Shaw 2006 \{published data only\}}

Shaw P, Sporn A, Gogtay N, Overman GP, Greenstein D, Gochman P, Tossell JW, Lenane M, Rapoport JL. Childhoodonset schizophrenia: a double-blind, randomized clozapineolanzapine comparison. Archives of General Psychiatry 2006;63(7):721-30. [MEDLINE: 16818861]

Xiong 2004 \{published data only\}

Xiong Y. Comparison study of childhood schizophrenia treated with risperidone and chlorpromazine. Guizhou Medical Journal 2004;28(8):697-698. [114314]

\section{Yao 2003 \{published data only\}}

Yao H. A study of risperidone in the treatment of child schizophrenia. Journal of Clinical Psychological Medicine 2003;7468(2):801. [MEDI0307]

\section{References to studies excluded from this review}

Claghorn 1972 \{published data only\}

${ }^{*}$ Claghorn JL. A double-blind comparison of haloperidol (haldol) and thioridazine (mellaril) in outpatient children. Current Therapeutic Research 1972;14(12):785-9. [MEDLINE: 4629817; PsycINFO 51-01570]

Fish 1966 \{published data only\}

* Fish B, Shapiro T, Campbell M. Long-term prognosis and the response of schizophrenic children to drug therapy: a controlled study of trifluoperazine. American Journal of Psychiatry 1966;123(1):32-9. [MEDLINE: 66135917]
Frazier 1994 \{published data only\}

* Frazier JA, Gordon CT, McKenna K, Lenane MC, Jih D, Rapoport JL. An open trial of clozapine in 11 adolescents with childhood onset schizophrenia. Journal of the American Academy of Child and Adolescent Psychiatry 1994;33(5):658-63. [MEDLINE: 8056728]

Gram 1972 \{published data only\}

* Gram LF, Rafaelsen OJ. Lithium treatment of psychotic children and adolescents. A controlled clinical trial. Acto Psychiatrica Scandinavica 1972;48(3):253-60. [MEDLINE: 4617490]

\section{Lewis 1972 \{published data only\}}

* Lewis PJ, James NM. Haloperidol and chlorpromazine - a double-blind cross-over trial and clinical study in children and adolescents. Australian and New Zealand Journal of Psychiatry 1973;7(1):59-65. [MEDLINE: 73233111]

\section{Liang 2003 \{published data only\}}

Liang L. A clinical trial of risperidone in treatment of childhood patients with first-episode schizophrenia. Journal of Clinical Psychological Medicine 2003;13(1):20-1. [MEDI0306]

\section{McGlashan 2003 \{published data only\}}

McGlashan TH, Zipursky RB, Perkins D, Addington J, Miller T, Woods SW, Hawkins KA, Hoffman RE, Preda A, Epstein L, Addington D, Lindborg S, Trzaskoma Q, Tohen M, Breier A. Randomized, double-blind trial of olanzapine versus placebo in patients prodromally symptomatic for psychosis. American Journal of Psychiatry 2006;163(5):790-9. [MEDLINE: 16648318]

McGlashan TH, Zipursky RB, Perkins DO, Addington J, Woods SW, Miller TJ, Lindborg S, Marquez E, Hawkins K, Hoffman RE. Olanzapine versus placebo treatment of the schizophrenia prodrome: One year results. Schizophrenia Research 2003;60:295. [MEDLINE: 16103032]

\section{Nagaraja 1977 \{published data only\}}

* Nagaraja J. Clinical use of haloperidol (serenace) in child psychiatry. Child Psychiatry Quarterly 1977;10(4):14-20. [PsycINFO 61-04251]

\section{Sikich 2004 \{published data only\}}

Sikich L, Hamer RM, Bashford RA, Sheitman BB, Lieberman JA A pilot study of risperidone, olanzapine, and haloperidol in psychotic youth: a double-blind, randomized, 8-week trial. Neuropyschopharmacology 2004;29(1):133-45. [MEDLINE: 14583740; EMBASE: 2004025276]

\section{Spencer 1996 \{published data only\}}

Spencer EK, Kafantaris V, Padron G, Maria V, Rosenberg CR. Haloperidol in hospitalized schizophrenic children. In: Richardson MA, Haugland G editor(s). Use of neuroleptics in children. Washington, USA: American Psychiatric Press Inc, 1996:67-83. [PsycINFO 95-364037-004]

Spencer EK, Kafantaris V, Padron-Gayol MV, Rosenberg CR, Campbell M. Haloperidol in schizophrenic children: early 
findings from a study in progress. Psychopharmacology Bulletin 1992;28(2):183-6. [MEDLINE: 1513922; PsycINFO 80-02673]

\section{Tandon 2005 \{published data only\}}

Tandon R, Sitholey P, Katiyar M, Kumar A. Short term tolerability of risperidone in children and adolescents with acute and transient psychotic disorders. XIII World Congress of Psychiatry; 2005 10-15th Sept; Cairo, Egypt. 2005. [P13.P250]

\section{van Nimwegen 2006 \{published data only\}}

van Nimwegen L, de Haan L. Early withdrawal in a doubleblind randomized clinical trial with olanzapine and risperidone performed in adolescents with first psychosis. Psychopathology 2006;39(3):158. [MEDLINE: 16531692; EMBASE 160407]

\section{References to studies awaiting assessment}

\section{Magnuson 2001 \{published data only\}}

Magnuson WG. Childhood onset psychotic disorders: characterization and treatment with atypical neuroleptics / Treatment of childhood onset psychotic disorders with olanzapine or clozapine. National Institutes of Health 2001. [National Institutes of Health (Study ID number) 97-M-0126; National Institutes of Health (NLM Identifier) NCT00001656]

\section{Additional references}

\section{AACAP 2001}

Mclellan J, Werry J, Bernet W, Arnold V, Beitchman J, Benson R, Buckstein O, Kinlan J, McClellan, Rue D, Shaw J. Practice parameter for the assessment and treatment of children and adolescents with schizophrenia. Journal of the American Academy of Child and Adolescent Psychiatry 2001;40(7 Supplement):4s-23s.

\section{Altman 1996}

Altman DG, Bland JM. Detecting skewness from summary information. British Medical Journal 1996;313:1200.

\section{Alvir 1993}

Alvir JM, Lieberman JA, Safferman AZ, Schwimmer JL, Schaaf JA. Clozapine induced agranulocytosis.. New England Journal of Medicine 1993;329:162-167.

\section{Andreasen 1983}

Andreasen NC. The Scale for the Assessment of Negative Symptoms (SANS). lowa City: The University of lowa 1983.

\section{Andreasen 1984}

Andreasen NC. The Scale for the Assessment of Positive Symptoms, (SAPS). Iowa City: The University of lowa 1984.

\section{APA 1980}

American Psychiatric Association. Diagnostic and Statistical Manual of Mental Disorders 3rd edition (DSM-III). Washington DC: American Psychiatric Association, 1980.

\section{APA 1994}

American Psychiatric Association. Diagnostic and Statistical Manual of Mental Disorders, 4th edition (DSM-IV). Washington, DC: American Psychiatric Association, 1994.

\section{Asarnow 1988}

Asarnow JR, Ben-Meir S. Children with schizophrenia spectrum and depressive disorders: a comparative study of premorbid adjustment, onset pattern and severity of impairment. Journal of Child Psychology and Psychiatry 1988;29:477-88.

\section{Asarnow 2004}

Asarnow Rosenbaum J, Tompson MC, McGrath EP. Annotation: Childhood-onset schizophrenia: clinical and treatment issues. Journal of Child Psychology and Psychiatry 2004;45(2):180-194.

\section{Baldessarini 1995}

Baldessarini RJ, Teicher M. Dosing of antipsychotic agents in paediatric populations. Journal of Child and Adolescent Psychopharmacology 1995;5(1):1-4.

\section{Beitchman 1985}

Beitchman JH. Childhood schizophrenia: a review and comparison with adult-onset schizophrenia. Psychiatric Clinics of North America 1985;8:793-814.

\section{Bland 1997}

Bland JM, Kerry SM. Statistics notes. Trials randomised in clusters. BMJ 1997;315:600.

\section{Bleuler 1911}

Bleuler E. Dementia praecox oder die gruppe der schizophrenien. Leipzig: Deuticke, 1911.

\section{Boissel 1999}

Boissel JP, Cucherat M, Li W, Chatellier G, Gueyffier F, Buyse M, Boutitie F, Nony P, Haugh M, Mignot G. The problem of therapeutic efficacy indices. 3. Comparison of the indices and their use. Therapie 1999;54(4):405-11.

\section{Bunney 1963}

Bunney WEJ, Hamburg DA. Methods for reliable longitudinal observation of behavior. Archives of General Psychiatry 1963;9:280-294.

\section{Burd 1987}

Burd L, Fischer W, Kerbeshian J. A prevalence study of pervasive developmental disorders in North Dakota. Journal of the American Academy of Child and Adolescent Psychiatry 1987;26(5):700-3.

\section{Calderoni 2001}

Calderoni D, Wudarsky M, Bhangoo R, Dell ML, Nicolson R, Hamburger S, Gochman P, et al. Differentating childhood-onset schizophrenia from psychotic mood disorders. Journal of the American Academy of Child and Adolescent Psychiatry October 2001;40(10):1191-7. 


\section{Chalmers 1983}

Chalmers TC, Celano P, Sacks HS, Smith H. Bias in treatment assignment in controlled clinical trials. New England Journal of Medicine 1983;309:1358-61.

\section{Clark 1988}

Clark A F, Lewis S W. Practitioner review: Treatment of schizophrenia in childhood and adolescence. Journal of Child Psychology and Psychiatry 1988;39(8):1071-81.

\section{Deeks 2000}

Deeks J. Issues in the selection for meta-analyses of binary data: Abstracts of 8th International Cochrane Colloquium. 2000 Oct 25-28th; Cape Town, South Africa.

\section{Divine 1992}

Divine GW, Brown JT, Frazer LM. The unit of analysis error in studies about physicians' patient care behavior. Journal of General Internal Medicine 1992;7:623-9.

\section{Donner 2002}

Donner A, Klar N. Issues in the meta-analysis of cluster randomized trials. Statistics in Medicine 2002;21:2971-80.

\section{Garralda 1984}

Garralda M. Hallucinations in children with conduct and emotional disorders; I. The clinical phenomena. Psychological Medicine 1984;14:589-96.

\section{Gillberg 1984}

Gillberg C. Infantile autism and other childhood psychoses in a sweedish urban region. Epidemiological aspects. Journal of Child Psychology and Psychiatry 1984;25:35-43.

\section{Gillberg 1987}

Gillberg C, Steffenburg S. Outcome and prognostic factors in infantile autism and similar conditions: a population-based study of 46 cases followed through puberty. Journal of Autism and Developmental Disorders 1987;17:273-87.

\section{Gillberg 2001}

Gillberg C. Epidemiology of early onset schizophrenia. In: Remschmidt $\mathrm{H}$ editor(s). Schizophrenia in children and adolescents. Ist. Cambridge: Cambridge University Press, 2001:43-54.

\section{Green 1992}

Green W, Padron-Gayol M, Hardesty A, Bassiri M. Schizophrenia with childhood onset: a phenomenological study of 38 cases. Journal of the American Academy of Child and Adolescent Psychiatry 1992;35:968-76.

\section{Gulliford 1999}

Gulliford MC, Ukoumunne OC, Chinn S. Components of variance and intraclass correlations for the design of communitybased surveys and intervention studies: data from the Health Survey for England 1994. American Journal of Epidemiology 1999;149:876-83.

\section{Guy 1976}

Guy U. ECDEU assessment manual for psychopharmacology. Revised. Rockville: National Institute of Mental Health, 1976.

\section{Hazell 1995}

Hazell Pl, O'Connell D, Heathcote D, Robertson J, Henry D. Efficacy of tricyclic drugs in treating child and adolescent depression. A meta-analysis. British Medical Journal 1995;310:897-901.

\section{Hazell 2001}

Hazell P, O'Connell D, Heathcote D, Henry D. Tricyclics in child and adolescent depression. Cochrane Database of Systematic Reviews 2001, Issue 3. [DOI: 10.1002/14651858.CD002317]

\section{Higgins 2003}

Higgins JPT, Thompson SG, Deeks JJ, Altman DG. Measuring inconsistency in meta-analyses.. BMJ 2003;327:557-60.

\section{Higgins 2005}

Higgins JPT. Cochrane Handbook for Systematic Reviews of Interventions 4.2.5 [updated May 2005]. In: Higgins JPT, Green S editor(s). The Cochrane Library. Chichester, UK: John Wiley \& Sons, Ltd., 2005.

\section{Hollis 1995}

Hollis C. Child and adolescent schizophrenia (juvenile onset) schizophrenia: a case control study of premorbid developmental impairments. British Journal of Psychiatry 1995;166:489-95.

\section{Hollis 2000}

Hollis C. Adolescent schizophrenia. Advances in Psychiatric Treatment 2000;6:83-92.

\section{Hollis 2001}

Hollis C. Diagnosis and differential diagnosis. In: Remschmidt $\mathrm{H}$ editor(s). Schizophrenia in children and adolescents. 1st Edition. Cambridge: Cambridge University Press, 2001.

\section{Jacobsen 1998}

Jacobsen LK, Rapoport JL. Research update: Childhood-onset schizophrenia: Implications of clinical and neurobiological research. Journal of Child Psychology and Psychiatry 1998;39(1):101-13.

\section{Jadad 1996}

Jadad A, Moore A, Carroll D, Jenkinson C, Reynolds DJM, Gavaghan DJ, McQuay HJ. Assessing the quality of reports of randomized clinical trials: is blinding necessary?. Controlled Clinical Trials 1996;17:1-12.

\section{Kane 1988}

Kane J, Honigfield G, Singer J, Meltzer H. Clozapine for treatment-resistant schizophrenia: a double-blind comparison with chlorpromazine.. Archives of General Psychiatry 1988;45:789-796.

\section{Kanner 1943}

Kanner L. Autistic disturbances of affective contact. Nervous child 1943;2:217-50. 


\section{Kanner 1949}

Kanner L. Problems of nosology and psychodynamics of early infantile autism. American Journal of Orthopsychiatry 1949;19:416-26.

\section{Kay 1987}

Kay SR, Fiszbein A, Opler LA. The positive and negative syndrome scale (PANSS) for schizophrenia. Schizophrenia Bulletin 1987;13:261-76.

\section{Kolvin 1971}

Kolvin I. Studies in the childhood psychoses: I. Diagnostic criteria and classification. British Journal of Psychiatry 1971;118:381-84.

\section{Kraeplin 1919}

Kraeplin E. Dementia praecox and paraphrenia (trans RM Barclay). Edinburgh: Livingstone, 1919.

\section{Kumra 1998}

Kumra S. Children and adolescents with psychotic disorders. Child Psychopharmacology. Washington DC: American Psychiatric Press, 1998.

\section{Marshall 2000}

Marshall M, Lockwood A, Bradley C, Adams C, Joy C, Fenton M. Unpublished rating scales: a major source of bias in randomised controlled trials of treatments for schizophrenia. British Journal of Psychiatry 2000;176:249-52.

\section{McKenna 1994}

Mckenna K, Gordon CT, Lenane M, Kaysan D, Fahey K, Rapoport J. Looking for childhood-onset schizophrenia: The first 71 cases screeened. Journal of the American Academy of Child and Adolescent Psychiatry June 1994;33(5):636-44.

\section{Moher 2001}

Moher D, Schultz KF, Altman DG. The CONSORT statement: revised recommendations for improving the quality of reports of parallel group randomised trials. Lancet 2001;357:1191-4.

\section{Montgomery 1979}

Montgomery SA, Asberg M. A new depression scale designed to be sensitive to change. British Journal of Psychiatry 1979;134:382-389.

\section{Overall 1962}

Overall JE, Gorham DR. The Brief Psychiatric Rating Scale. Psychological Reports 1962;10:799-812.

\section{Parry-Jones 2001}

Parry-Jones WL. Childhood psychosis and schizophrenia: a historical review. In: Remschmidt H editor(s). Schizophrenia in children and adolescents. Ist. Cambridge: Cambridge University Press, 2001:1-23.

\section{Remschmidt 1995}

Remschmidt H, Schulz E. Psychopharmacology of depressive states in childhood and adolescence. The depressed child and adolescent : Developmental and clinical perspectives. Cambridge: Cambridge University Press, 1995:253-79.

\section{Riddle 2001}

Riddle MA, Kaselic EA, Frosch E. Paediatric psychopharmocology. Journal of Child Psychology and Psychiatry 2001;42(1):73-90.

\section{Russell 1994}

Russell AT. The clinical presentation of childhood-onset schizophrenia. Schizophrenia Bulletin 1994;20:631-46.

\section{Rutter 1967}

Rutter M, Greenfield D, Lockyer L. A five to fifteen year study of infantile psychosis. II. Social behavioural outcome. British Journal of Psychiatry 1967;113:1183-99.

\section{Rutter 1972}

Rutter M. Childhood schizophrenia reconsidered. Journal of Autism \& Childhood Schizophrenia 1972;2:315-37.

\section{Schaffer 1983}

Schaffer D, Gould MS, Brasic J. A children's global assessment scale (CGAS). Archives of General Psychiatry 1983;40:1228-1231.

\section{Schulz 1995}

Schulz KF, Chalmers I, Hayes RJ, Altman DG. Empirical evidence of bias: dimensions of methodological quality associated with estimates of treatment effects in controlled trials. JAMA 1995;273:408-12.

\section{Simpson 1970}

Simpson GM, Angus JWS. A rating scale for extrapyramidal side effects. Acta Psychiatrica Scandinavica AActa Psychiatrica Scandinavica 1970;Suppl 212:11-19.

\section{Ukoumunne 1999}

Ukoumunne OC, Gulliford MC, Chinn S, Sterne JAC, Burney PGJ. Methods for evaluating area-wide and organisation-based interventions in health and health care: a systematic review. Health Technology Assessment 1999;3(5):iii-92.

\section{Usiskin 1999}

Usiskin SI, Nicolson R, Krasnewich DM, Wenliang Y, Lenane M, Wudarsky M, Hamburger S, Rapoport J. Velocardiofacial syndrome in childhood-onset schizophrenia. Journal of the American Academy of Child and Adolescent Psychiatry 1999;38(12):1536-43.

\section{Volkmar 2001}

Volkmar FR. Childhood schizophrenia: developmental aspects. In: Remschmidt $\mathrm{H}$ editor(s). Schizophrenia in children and adolescents. 1st Edition. Cambridge: Cambridge University Press, 2001.

\section{Waraich 2002}

Waraich PS, Adams CE, Roque M, Hamill KM, Marti J. Haloperidol dose for the acute phase of schizophrenia. Cochrane Database of Systematic Reviews 2002, Issue 4. [DOI: 10.1002/14651858.CD001951] 


\section{Watkins 1988}

Watkins JM, Asarnow RF, Tanguay P. Symptom development in childhood onset schizophrenia. Journal of Child Psychiatry and Psychology 1988;29:865-978.

\section{Werry 1992}

Werry JS. Child and adolescent (early onset) schizophrenia: a review in light of DSM-IIIR. Journal of Autism and Developmental Disorders 1992;22:601-24.

\section{WHO 1978}

World Health Organisation. International Classification of Diseases (9th Revision) of Mental and Behavioural Disorders. Geneva: WHO, 1978.

\section{WHO 1992}

World Health Organization. The ICD-10 classification of mental and behavioural disorders. Clinical descriptions and diagnostic guidelines. Geneva: WHO, 1992.

* Indicates the major publication for the study

\section{CHARACTERISTICS OF STUDIES}

Characteristics of included studies [ordered by study ID]

\section{Engelhardt 1973}

\begin{tabular}{|c|c|c|}
\hline Methods & \multicolumn{2}{|c|}{$\begin{array}{l}\text { Allocation: randomised,. } \\
\text { Blindness: double but not formally assessed. } \\
\text { Duration: } 12 \text { weeks. } \\
\text { Design: singlecentre. } \\
\text { Country: USA. }\end{array}$} \\
\hline Participants & \multicolumn{2}{|c|}{$\begin{array}{l}\text { Diagnosis: childhood schizophrenia. } \\
\mathrm{N}=30 \text {. } \\
\text { Age: range } 6-12 \text { years. } \\
\text { Sex: } 26 \text { male, } 4 \text { female. } \\
\text { Exclusion criteria: children whose symptamatology was primarily due to brain damage or mental retar- } \\
\text { dation, and psychotic children attending public schools. } \\
\text { Setting: outpatient. }\end{array}$} \\
\hline Interventions & \multicolumn{2}{|c|}{$\begin{array}{l}\text { 1. Fluphenazine: } \text { mean } 10.4 \mathrm{mg} / \text { day. } \mathrm{N}=15 \text {. } \\
\text { 2. Haloperidol: } \text { mean } 10.4 \mathrm{mg} / \text { day. } \mathrm{N}=15 \text {. }\end{array}$} \\
\hline Outcomes & \multicolumn{2}{|c|}{$\begin{array}{l}\text { Global state: CGI. } \\
\text { Mental state: CPRS. } \\
\text { Adverse effects: TESS. } \\
\text { Unable to use: } \\
\text { Haematology and biochemistry. }\end{array}$} \\
\hline \multicolumn{3}{|l|}{ Notes } \\
\hline \multicolumn{3}{|l|}{ Risk of bias } \\
\hline Bias & Authors' judgement & Support for judgement \\
\hline $\begin{array}{l}\text { Allocation concealment } \\
\text { (selection bias) }\end{array}$ & Unclear risk & B - Unclear \\
\hline
\end{tabular}

Faretra 1970

\begin{tabular}{ll}
\hline Methods & Allocation: randomised, method not described. \\
Blindness: double (medications prepared in identical capsules and stored in bottles identified only by \\
number). \\
Duration: 8 weeks.
\end{tabular}


Faretra 1970 (Continued)

Design: singlecentre.

Country: USA.

\section{Participants}

Diagnosis: childhood schizophrenia, psychosis with organic brain damage, psychosis with mental deficiency and primary behaviour disorder. $87 \%$ of the participants had the diagnosis of schizophrenia.

$\mathrm{N}=60$.

Age: range 5-12 years.

Sex: 44 male, 16 female.

Inclusion criteria: participants have to be 12 years or younger, they have been hospitalised at least three months but no longer than six years, have no history of convulsive disorder, have symptoms considered to be psychotic.

Setting: inpatient.

\begin{tabular}{ll}
\hline Interventions & 1. Fluphenazine: upto $1.25 \mathrm{mg}$ three times a day. $\mathrm{N}=30$. \\
& 2. Haloperidol: upto $1.25 \mathrm{mg}$ three times a day. $\mathrm{N}=30$. \\
\hline Outcomes & Global state: $\mathrm{CGI}$. \\
& Adverse effects. \\
& Unable to use: \\
& Haematology and biochemistry. \\
\hline
\end{tabular}

Notes

\section{Risk of bias}

\begin{tabular}{lll}
\hline Bias & Authors' judgement & Support for judgement \\
\hline $\begin{array}{l}\text { Allocation concealment } \\
\text { (selection bias) }\end{array}$ & Unclear risk & B - Unclear \\
\hline
\end{tabular}

Kumra 1996

Allocation: randomised undertaken by Pharmacy using a table of random numbers.
Blindness: double. Patients on haloperidol recieved propylactic benztropine and those on clozapine
identical placebo to enhance blinding. The success of blinding was not formally assessed.
Duration: 6 weeks.
Design: singlecentre.
Country: USA.

\begin{tabular}{ll}
\hline Participants & Diagnosis: Disorganised, undifferentiated, paranoid schizophrenia (DSM-III). \\
N=21. & Age: range 6-18 years. \\
Sex: 11 male, 10 female. \\
Inclusion criteria: Diagnosis of schizophrenia defined by the DSM-III, with documented psychotic symp- \\
toms by age 12 years; intolerance, nonresponse, or both to at least 2 different neuroleptic drugs; and a \\
full scale of IQ of 70 or more. \\
Exclusion criteria: Neurologic or medical disease. \\
Setting: inpatient. \\
\hline 1. Clozapine: mean dose $176+-149 \mathrm{mg} /$ day, range $25-525 \mathrm{mg} /$ day. $\mathrm{N}=10$. \\
2. Haloperidol: mean dose $16+-8 \mathrm{mg} /$ day, range $7-27 \mathrm{mg} /$ day. $\mathrm{N}=11$. \\
\hline Outcomes & Leaving the study. \\
Global state: CGI, C-GAS. \\
Mental state: BPRS, SANS, SAPS, The Bunney-Hamburg Psychosis Assessment Scale, Simpson-Angus \\
Neurological Rating Scale.
\end{tabular}


Kumra 1996 (Continued)

Adverse effects: Subjective Treatment Emergent Symptom Scale, Abnormal Involuntary Movement Scale (AIMS).

\section{Notes}

\section{Risk of bias}

\begin{tabular}{lll}
\hline Bias & Authors' judgement & Support for judgement \\
\hline $\begin{array}{l}\text { Allocation concealment } \\
\text { (selection bias) }\end{array}$ & Unclear risk & B - Unclear \\
\hline
\end{tabular}

\section{Shaw 2006}

Methods
Allocation: randomised. Clearly described. Allocation concealed. Pharmacy generated allocation se-
Blindness: double. The success of blinding was not formally assessed.
Duration: 8 weeks.
Design: multicentre.
Country: USA.
Participants Diagnosis: childhood onset schizophrenia (Schedule for schizophrenia for School-Age Children). $\mathrm{N}=25$.
Age: range $7-16$ years.
Sex: 15 male, 10 female.
Inclusion criteria: Diagnosis of schizophrenia with a definite onset of symptoms before 13 years of age, IQ greater than 70 , no history of progressive neurological or medical disorders such as epilepsy, and failure to respond to 2 antipsychotic medications (typical or atypical) used at adequate doses (>100mg chlorpromazine equivalents) and for adequate duration (>=4 weeks unless terminated owing to intoler- able adverse effects).
Exclusion criteria: Nonresponse to adequate trial of clozapine or olanzapine. Setting: inpatient.

Interventions Clozapine: mean dose $327 \mathrm{mg} /$ day, range $150-500 \mathrm{mg} /$ day. $\mathrm{N}=12$.
2. Olanzapine: mean dose $18.1 \mathrm{mg} /$ day, range $5-20 \mathrm{mg} /$ day. $\mathrm{N}=13$.

Lutcomes
Global state: CGI-S.
Mental State: SANS,SAPS.
Adverse effects.
Unable to use:
Mental state: BPRS (no usable data).
The Bunny-Hamburg Psychosis, Depression, Mania, and Anxiety Rating Scales (no usable data).

\section{Notes}

\section{Risk of bias}

\begin{tabular}{lll}
\hline Bias & Authors' judgement & Support for judgement \\
\hline $\begin{array}{l}\text { Allocation concealment } \\
\text { (selection bias) }\end{array}$ & Low risk & A-Adequate \\
\hline
\end{tabular}


Xiong 2004

\begin{tabular}{|c|c|c|}
\hline Methods & \multicolumn{2}{|l|}{$\begin{array}{l}\text { Allocation: randomised. } \\
\text { Blindness: not clear. } \\
\text { Duration: } 8 \text { weeks. } \\
\text { Design: single centre. } \\
\text { Country: China. }\end{array}$} \\
\hline Participants & \multicolumn{2}{|c|}{$\begin{array}{l}\text { Diagnosis: childhood onset schizophrenia (CCMD-II-R). } \\
\mathrm{N}=60 \text {. } \\
\text { Age: range } 7-16 \text { years. } \\
\text { Mean age: } 13 \text { years } \\
\text { Length of illness } 9-9.5 \text { years } \\
\text { Sex: } 34 \text { male, } 26 \text { female. } \\
\text { Inclusion criteria: children with the diagnosis of schizophrenia according to CCMD-II-R, should be be- } \\
\text { tween } 7-16 \text { years of age, without any physical problems or any organic neurological disease. } \\
\text { Setting: inpatient. }\end{array}$} \\
\hline Interventions & \multicolumn{2}{|c|}{$\begin{array}{l}\text { 1. Risperidone: dose range } 0.5-5 \mathrm{mg} / \mathrm{day} . \mathrm{N}=30 \text {. } \\
\text { 2. Chlorpromazine: dose range } 50-400 \mathrm{mg} / \text { day. } \mathrm{N}=30 \text {. }\end{array}$} \\
\hline Outcomes & \multicolumn{2}{|l|}{$\begin{array}{l}\text { Mental state: BPRS. } \\
\text { Adverse effects: TESS. }\end{array}$} \\
\hline \multicolumn{3}{|l|}{ Notes } \\
\hline \multicolumn{3}{|l|}{ Risk of bias } \\
\hline Bias & Authors' judgement & Support for judgement \\
\hline $\begin{array}{l}\text { Allocation concealment } \\
\text { (selection bias) }\end{array}$ & Unclear risk & B - Unclear \\
\hline
\end{tabular}

Yao 2003

\begin{tabular}{ll} 
Methods & $\begin{array}{l}\text { Allocation: randomised. } \\
\text { Blindness: not clear. } \\
\text { Duration: } 6 \text { weeks. } \\
\text { Design: single centre. } \\
\text { Country: China. }\end{array}$ \\
\hline Participants & Diagnosis: childhood onset schizophrenia. \\
& N=60. \\
& Age: mean age 11 years. \\
& Sex: 23 male, 19 female, Others not specified. \\
& Setting: inpatient and outpatient. \\
\hline Interventions & 1. Risperidone: dose range $0.25-3 \mathrm{mg} /$ day. $\mathrm{N}=21$. \\
& 2. Haloperidol: dose range $0.5-12 \mathrm{mg} /$ day. $\mathrm{N}=21$.
\end{tabular}

\begin{tabular}{ll}
\hline Outcomes & Mental state: BPRS. \\
& Adverse effects: TESS
\end{tabular}

\section{Notes}

\section{Risk of bias}


Yao 2003 (Continued)

\begin{tabular}{lll} 
Bias & Authors' judgement & Support for judgement \\
\hline $\begin{array}{l}\text { Allocation concealment } \\
\text { (selection bias) }\end{array}$ & Unclear risk & B - Unclear
\end{tabular}

BPRS - Brief Psychiatric Rating Scale

C-GAS - Children's Global Assessment Scale

CGI - Clincal Global Impression Scale

CPRS - Child Psychiatric Rating Scale

SANS - Scale for the Assessment of Negative Symptoms

SAPS - Scale for the Assessment of Positive Symptoms

TESS - Treatment Emergent Symptoms Scale

Characteristics of excluded studies [ordered by study ID]

\begin{tabular}{ll}
\hline Study & Reason for exclusion \\
\hline Claghorn 1972 & Allocation: randomised, double-blind. \\
& Participants: children with hyperactivity, mental retardation, minor brain injury, behavioural prob- \\
lems and schizophrenia. & Outcome: global assessment of response, vitals (BP, pulse etc.), biochemistry and adverse effects. \\
& No separate data for participants with the diagnosis of schizophrenia. \\
\hline
\end{tabular}

\begin{tabular}{ll}
\hline Fish 1966 & Allocation: not randomised. \\
\hline Frazier 1994 & Allocation: not randomised. \\
\hline Gram 1972 & $\begin{array}{l}\text { Allocation: randomised, double-blind. } \\
\text { Participants: children with psychosis, borderline disorder, oligophrenia and personality disorder. } \\
\text { No participants with formal diagnosis of schizophrenia. }\end{array}$ \\
\hline
\end{tabular}

Lewis $1972 \quad$ Allocation: randomisation not clear, double-blind.

Participants: children with neurosis, psychosis, situational disorder and behaviour disorder. No participants with formal diagnosis of schizophrenia.

\begin{tabular}{ll}
\hline Liang 2003 & Allocation: not randomised. \\
\hline McGlashan 2003 & $\begin{array}{l}\text { Allocation: randomised, double-blind. } \\
\text { Participants: children with schizophrenia meeting prodromal criteriaby by the Structured Interview } \\
\text { for Prodromal Syndromes, mean age } 17.7 \text { years, minimum age was } 13 \text { years. Only one participant } \\
\text { below the age of } 12 \text { years was enrolled but not separate data reported }\end{array}$ \\
\hline
\end{tabular}

Nagaraja 1977

Allocation: randomisation not clear.

Participants: children with psychosis, psychoneurosis, acute anxiety and behavioural disorder. No participants with formal diagnosis of schizophrenia.

\section{Sikich $2004 \quad$ Allocation: randomised, double blind.}

Participants: children and adolescents with psychotic symptoms. participant age group was between 8 years and 19 years. Age specific data unavailable.

\section{Spencer 1996}

Allocation: randomised, double blind, cross over study.

Participants: children with schizophrenia.

Outcome: CGI, CPRS, BPRS-C, AIMS, Simpson abbreviated dyskinesia rating scale. No data before cross over.

Tandon $2005 \quad$ Allocation: randomised, double-blind.




\begin{tabular}{|c|c|}
\hline Study & Reason for exclusion \\
\hline & $\begin{array}{l}\text { Participants: children with acute \& transient psychotic disorder. } \\
\text { Intervention: risperidone versus placebo. } \\
\text { Outcome: no data comparing groups available from abstracts. Correspondance author did not re- } \\
\text { spond to our request for the full paper. }\end{array}$ \\
\hline van Nimwegen 2006 & $\begin{array}{l}\text { Allocation: randomised, double-blind. } \\
\text { Participants: Adolescents with first-episode psychosis, no children. }\end{array}$ \\
\hline
\end{tabular}

* Author contacted - thanks for reply.

Characteristics of studies awaiting assessment [ordered by study ID]

Magnuson 2001

Methods

Participants

Interventions

Outcomes

Notes

awaiting details

DATA AND ANALYSES

Comparison 1. ATYPICAL vs TYPICAL ANTIPSYCHOTICS (only short term)

\begin{tabular}{|c|c|c|c|c|}
\hline Outcome or subgroup title & $\begin{array}{l}\text { No. of } \\
\text { studies }\end{array}$ & $\begin{array}{l}\text { No. of } \\
\text { partici- } \\
\text { pants }\end{array}$ & Statistical method & Effect size \\
\hline $\begin{array}{l}1 \text { Global state: } 1 \text {. Worse or no improve- } \\
\text { ment (CGI) }\end{array}$ & 1 & 21 & Risk Ratio (M-H, Fixed, 95\% Cl) & $3.3[0.41,26.81]$ \\
\hline $\begin{array}{l}2 \text { Global state: } 2 . \text { Mean end point score } \\
\text { (Children Global Assessment Scale, high } \\
\text { score=good) }\end{array}$ & 1 & 21 & Mean Difference (IV, Fixed, 95\% CI) & $17.0[7.74,26.26]$ \\
\hline 3 Mental state: 1 . No improvement (BPRS) & 1 & 60 & Risk Ratio (M-H, Fixed, 95\% Cl) & $1.2[0.41,3.51]$ \\
\hline $\begin{array}{l}4 \text { Mental state: } 2 \text {. Mean end point score } \\
\text { (BPRS, high score = poor) }\end{array}$ & 3 & 123 & Mean Difference (IV, Fixed, 95\% CI) & $-1.71[-3.51,0.10]$ \\
\hline $\begin{array}{l}5 \text { Mental state: } 3 . \text { Mean end point score } \\
\text { (SANS, data skewed, high score }=\text { poor) }\end{array}$ & & & Other data & No numeric data \\
\hline $\begin{array}{l}6 \text { Mental state: } 4 . \text { Mean end point score } \\
\text { (SAPS, data skewed, high score }=\text { poor) }\end{array}$ & & & Other data & No numeric data \\
\hline
\end{tabular}




\begin{tabular}{|c|c|c|c|c|}
\hline Outcome or subgroup title & $\begin{array}{l}\text { No. of } \\
\text { studies }\end{array}$ & $\begin{array}{l}\text { No. of } \\
\text { partici- } \\
\text { pants }\end{array}$ & Statistical method & Effect size \\
\hline $\begin{array}{l}7 \text { Mental state: } 5 \text {. Mean end point score } \\
\text { (The Bunny-Hamburg Psychosis Rating } \\
\text { Scale, high score=poor) }\end{array}$ & 1 & 21 & Mean Difference (IV, Fixed, 95\% CI) & $-3.60[-6.64,-0.56]$ \\
\hline $\begin{array}{l}8 \text { Adverse effects: } 1 \text {. All adverse efects } \\
\text { (TESS) }\end{array}$ & 1 & 42 & Risk Ratio (M-H, Fixed, 95\% Cl) & $0.49[0.31,0.76]$ \\
\hline $\begin{array}{l}9 \text { Adverse effects: } 2 \text { a. Extrapyramidal ad- } \\
\text { verse effects (TESS) }\end{array}$ & 2 & & Risk Ratio (M-H, Fixed, 95\% Cl) & Subtotals only \\
\hline 9.1 Any Extrapyramidal side effects & 1 & 42 & Risk Ratio (M-H, Fixed, 95\% Cl) & $0.12[0.04,0.37]$ \\
\hline 9.2 restlessness & 1 & 60 & Risk Ratio (M-H, Fixed, 95\% Cl) & $1.5[0.27,8.34]$ \\
\hline 9.3 tremor & 1 & 60 & Risk Ratio (M-H, Fixed, 95\% Cl) & $0.5[0.05,5.22]$ \\
\hline $\begin{array}{l}10 \text { Adverse effects: } 2 b . \text { Extrapyramidal av- } \\
\text { erage score (end point, high score = poor) }\end{array}$ & 1 & & Mean Difference (IV, Fixed, 95\% CI) & Subtotals only \\
\hline 10.1 AIMS & 1 & 21 & Mean Difference (IV, Fixed, 95\% CI) & $-0.10[-3.72,3.52]$ \\
\hline $\begin{array}{l}\text { 10.2 Simpson-Angus Neurological Rating } \\
\text { Scale }\end{array}$ & 1 & 21 & Mean Difference (IV, Fixed, 95\% CI) & $-1.90[-4.19,0.39]$ \\
\hline $\begin{array}{l}11 \text { Adverse effects: } 3 \text {. Somno- } \\
\text { lence/drowsiness (TESS) }\end{array}$ & 3 & 123 & Risk Ratio (M-H, Fixed, 95\% Cl) & $0.56[0.30,1.03]$ \\
\hline $\begin{array}{l}12 \text { Adverse effects: } 4 \text {. Anticholinergic ad- } \\
\text { verse effects (TESS) }\end{array}$ & 3 & & Risk Ratio (M-H, Fixed, 95\% Cl) & Subtotals only \\
\hline 12.1 constipation & 2 & 102 & Risk Ratio (M-H, Fixed, 95\% Cl) & $0.17[0.02,1.33]$ \\
\hline 12.2 dizziness & 2 & 102 & Risk Ratio (M-H, Fixed, 95\% Cl) & $0.27[0.08,0.90]$ \\
\hline 12.3 dry mouth & 2 & 102 & Risk Ratio (M-H, Fixed, 95\% Cl) & $0.2[0.05,0.75]$ \\
\hline 12.4 low blood pressure & 1 & 60 & Risk Ratio (M-H, Fixed, 95\% Cl) & $0.2[0.01,4.00]$ \\
\hline $\begin{array}{l}12.5 \text { tachycardia (resting heart rate }>=100 \\
\text { beats/minute) }\end{array}$ & 1 & 21 & Risk Ratio (M-H, Fixed, 95\% Cl) & $1.54[0.72,3.31]$ \\
\hline $\begin{array}{l}13 \text { Adverse effects: } 5 \text {. Hypersalivation } \\
\text { (TESS) }\end{array}$ & 2 & 81 & Risk Ratio (M-H, Fixed, 95\% Cl) & $1.22[0.49,3.08]$ \\
\hline $\begin{array}{l}14 \text { Adverse effects: } 6 \text {. Drop in the absolute } \\
\text { neutrophil count below } 1500 \mathrm{~mm} \text { cube }\end{array}$ & 1 & 21 & Risk Ratio (M-H, Fixed, 95\% Cl) & $12.00[0.75,192.86]$ \\
\hline 15 Adverse effects: 7 . Seizure & 1 & 21 & Risk Ratio (M-H, Fixed, 95\% Cl) & $5.45[0.29,101.55]$ \\
\hline $\begin{array}{l}16 \text { Leaving the study early: } 1 \text {. Due to ad- } \\
\text { verse effects }\end{array}$ & 1 & 21 & Risk Ratio (M-H, Fixed, 95\% Cl) & $3.3[0.41,26.81]$ \\
\hline $\begin{array}{l}17 \text { Leaving the study early: } 2 \text {. Due to neu- } \\
\text { roleptic malignant syndrome }\end{array}$ & 1 & 21 & Risk Ratio (M-H, Fixed, 95\% Cl) & $0.36[0.02,8.03]$ \\
\hline
\end{tabular}




\begin{tabular}{lllll}
\hline Outcome or subgroup title & $\begin{array}{l}\text { No. of } \\
\text { studies }\end{array}$ & $\begin{array}{l}\text { No. of } \\
\text { partici- } \\
\text { pants }\end{array}$ & Statistical method & Effect size \\
\hline $\begin{array}{l}18 \text { Leaving the study early: 3. Due to drop } \\
\text { in neutrophil count }\end{array}$ & 1 & 21 & Risk Ratio (M-H, Fixed, 95\% Cl) & $5.45[0.29,101.55]$ \\
\hline
\end{tabular}

Analysis 1.1. Comparison 1 ATYPICAL vs TYPICAL ANTIPSYCHOTICS (only short term), Outcome 1 Global state: 1 . Worse or no improvement (CGI).

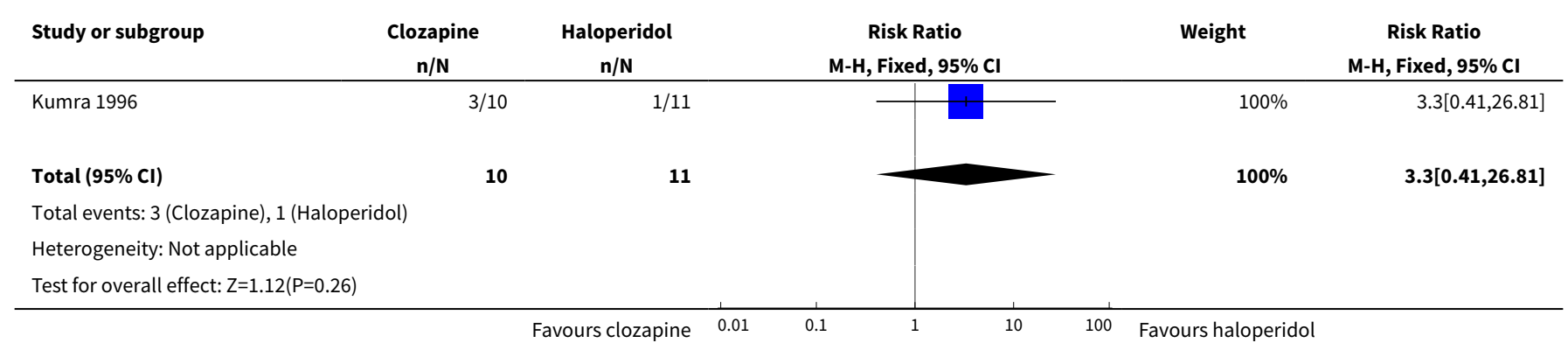

Analysis 1.2. Comparison 1 ATYPICAL vs TYPICAL ANTIPSYCHOTICS (only short term), Outcome 2 Global state: 2 . Mean end point score (Children Global Assessment Scale, high score=good).

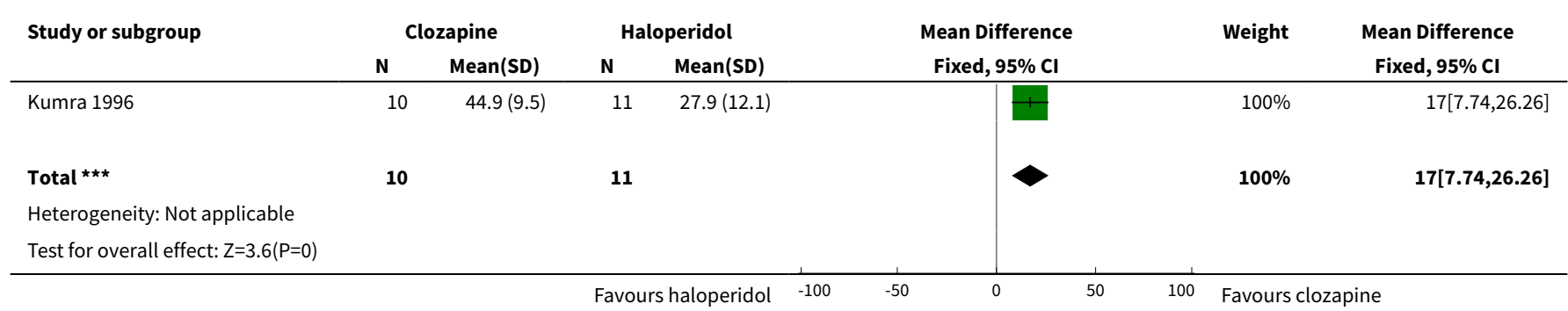

Analysis 1.3. Comparison 1 ATYPICAL vs TYPICAL ANTIPSYCHOTICS (only short term), Outcome 3 Mental state: 1. No improvement (BPRS).

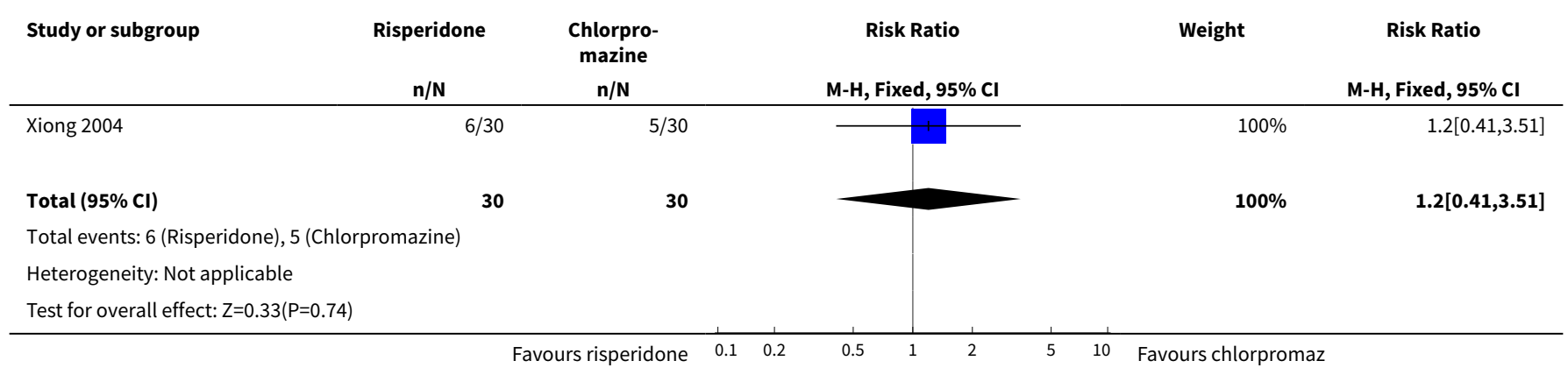


Analysis 1.4. Comparison 1 ATYPICAL vs TYPICAL ANTIPSYCHOTICS (only short term), Outcome 4 Mental state: 2. Mean end point score (BPRS, high score = poor).

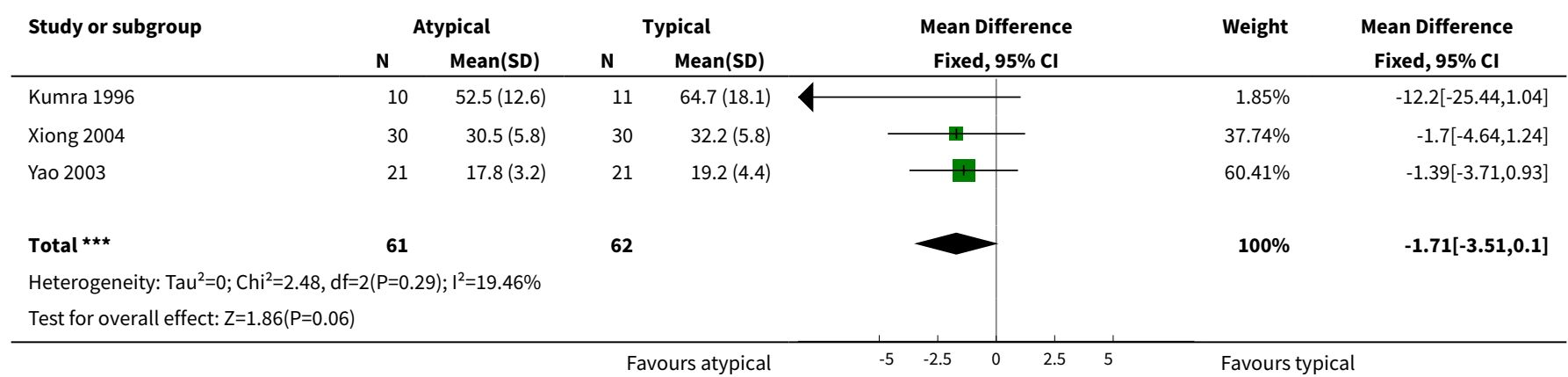

Analysis 1.5. Comparison 1 ATYPICAL vs TYPICAL ANTIPSYCHOTICS (only short term), Outcome 5 Mental state: 3. Mean end point score (SANS, data skewed, high score = poor).

\begin{tabular}{|c|c|c|c|c|}
\hline \multicolumn{5}{|c|}{ Mental state: 3 . Mean end point score (SANS, data skewed, high score = poor) } \\
\hline Study & Treatment & $\mathbf{N}$ & Mean & SD \\
\hline Kumra 1996 & Clozapine & 10 & 46.00 & 30.3 \\
\hline Kumra 1996 & Haloperidol & 11 & 72.2 & 24.7 \\
\hline
\end{tabular}

Analysis 1.6. Comparison 1 ATYPICAL vS TYPICAL ANTIPSYCHOTICS (only short term), Outcome 6 Mental state: 4. Mean end point score (SAPS, data skewed, high score = poor).

\begin{tabular}{lllll} 
& \multicolumn{4}{c}{ Mental state: 4. Mean end point score (SAPS, data skewed, high score $=$ poor) } \\
Study & Treatment & N & Mean \\
\hline Kumra 1996 & Clozapine & 10 & 19.1 & \\
\hline Kumra 1996 & Haloperidol & 11 & 35.9 & 11.7 \\
\hline
\end{tabular}

Analysis 1.7. Comparison 1 ATYPICAL vs TYPICAL ANTIPSYCHOTICS (only short term), Outcome 7 Mental state: 5. Mean end point score (The Bunny-Hamburg Psychosis Rating Scale, high score=poor).

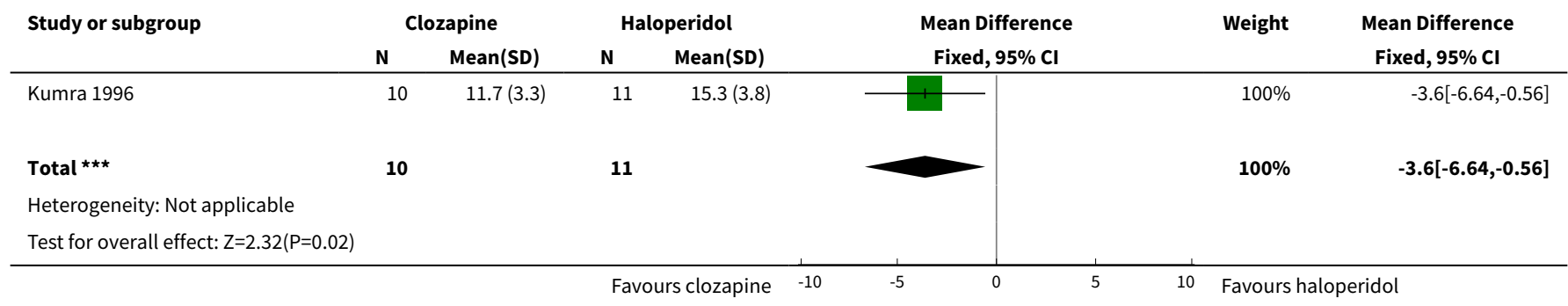


Analysis 1.8. Comparison 1 ATYPICAL vs TYPICAL ANTIPSYCHOTICS (only short term), Outcome 8 Adverse effects: 1 . All adverse efects (TESS).

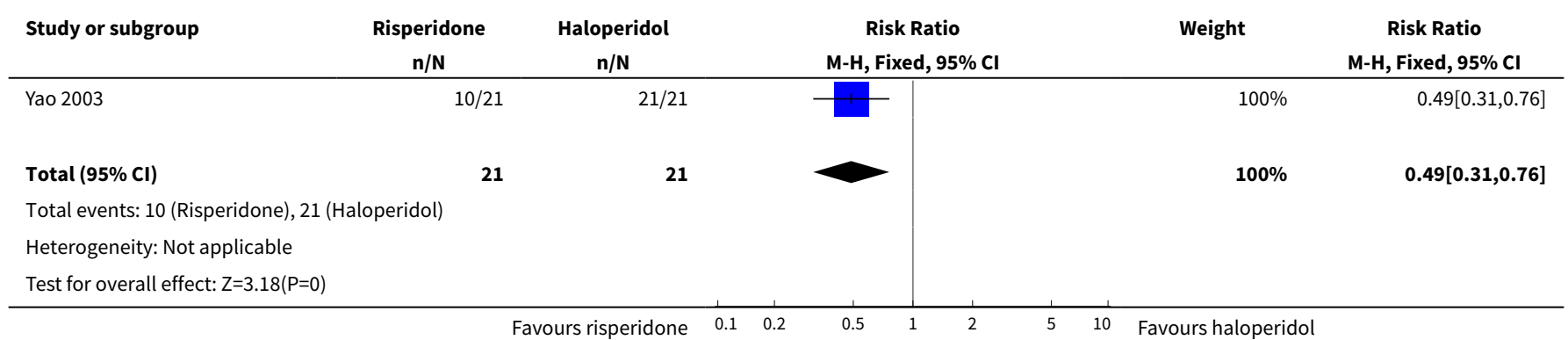

Analysis 1.9. Comparison 1 ATYPICAL vs TYPICAL ANTIPSYCHOTICS (only short term), Outcome 9 Adverse effects: $2 a$. Extrapyramidal adverse effects (TESS).

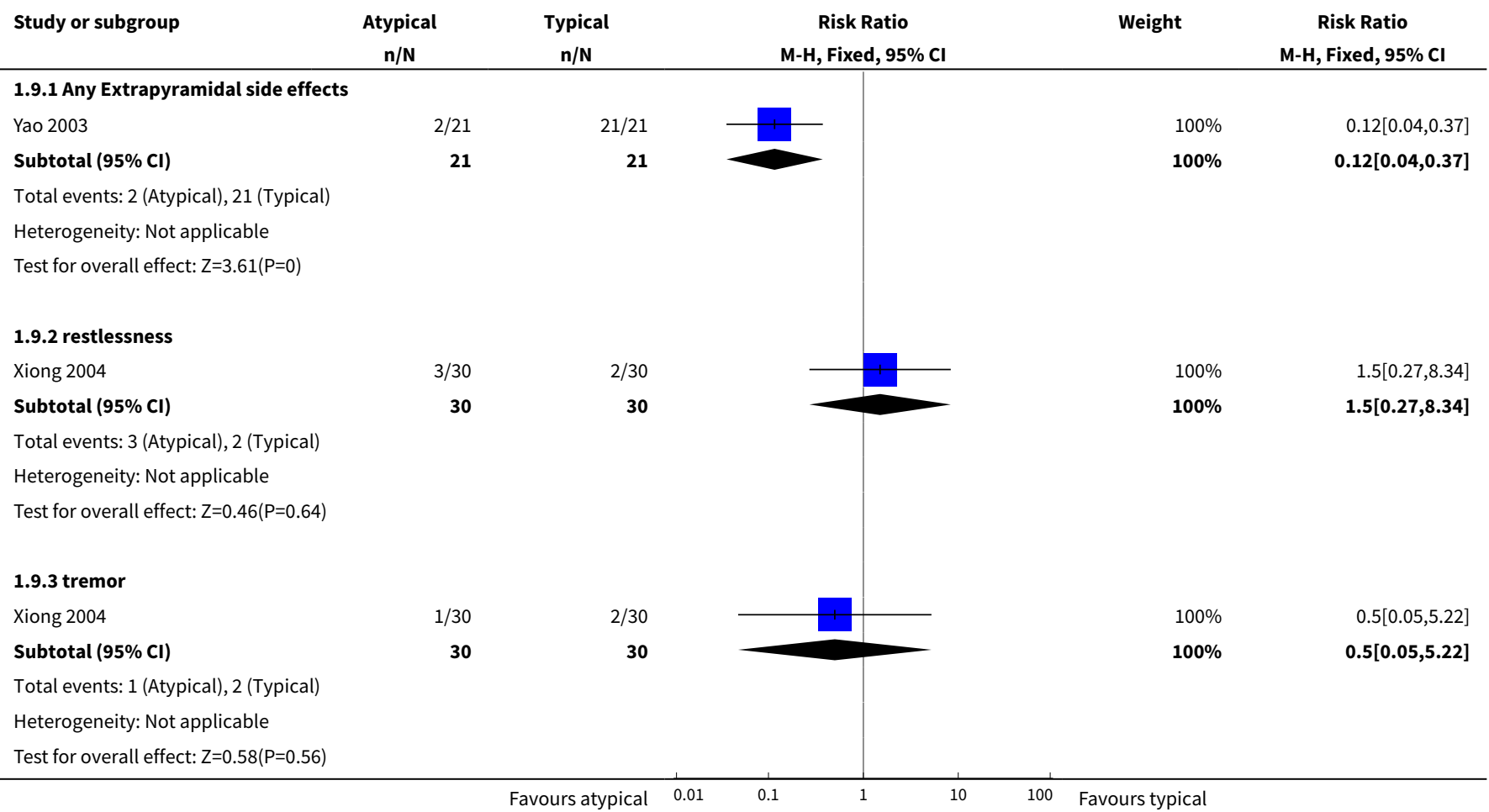

Analysis 1.10. Comparison 1 ATYPICAL vs TYPICAL ANTIPSYCHOTICS (only short term), Outcome 10 Adverse effects: 2b. Extrapyramidal average score (end point, high score $=$ poor).

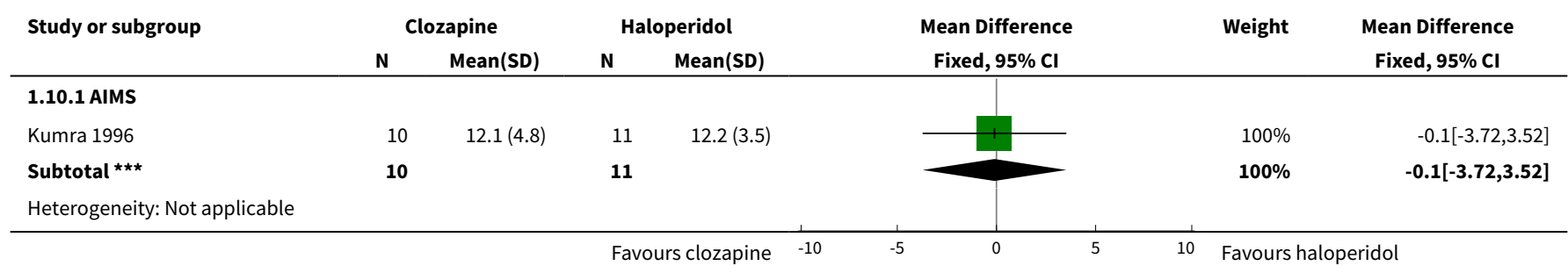




\begin{tabular}{|c|c|c|c|c|c|c|c|}
\hline \multirow[t]{2}{*}{ Study or subgroup } & \multicolumn{2}{|c|}{ Clozapine } & \multicolumn{2}{|c|}{ Haloperidol } & \multirow{2}{*}{$\begin{array}{c}\text { Mean Difference } \\
\text { Fixed, } 95 \% \mathrm{Cl}\end{array}$} & \multirow[t]{2}{*}{ Weight } & \multirow{2}{*}{$\begin{array}{c}\text { Mean Difference } \\
\text { Fixed, } 95 \% \mathrm{Cl}\end{array}$} \\
\hline & $\mathbf{N}$ & Mean(SD) & $\mathbf{N}$ & Mean(SD) & & & \\
\hline \multicolumn{5}{|c|}{ Test for overall effect: $Z=0.05(P=0.96)$} & & & \\
\hline \multicolumn{8}{|c|}{ 1.10.2 Simpson-Angus Neurological Rating Scale } \\
\hline Kumra 1996 & 10 & $12(1.6)$ & 11 & $13.9(3.5)$ & & $100 \%$ & $-1.9[-4.19,0.39]$ \\
\hline Subtotal $\star \star \star$ & 10 & & 11 & & & $100 \%$ & $-1.9[-4.19,0.39]$ \\
\hline \multicolumn{8}{|c|}{ Heterogeneity: Not applicable } \\
\hline \multicolumn{8}{|c|}{ Test for overall effect: $Z=1.62(P=0.1)$} \\
\hline \multicolumn{8}{|c|}{ Test for subgroup differences: $\mathrm{Chi}^{2}=0.68, \mathrm{df}=1(\mathrm{P}=0.41), \mathrm{I}^{2}=0 \%$} \\
\hline
\end{tabular}

Analysis 1.11. Comparison 1 ATYPICAL vs TYPICAL ANTIPSYCHOTICS (only short term), Outcome 11 Adverse effects: 3. Somnolence/drowsiness (TESS).

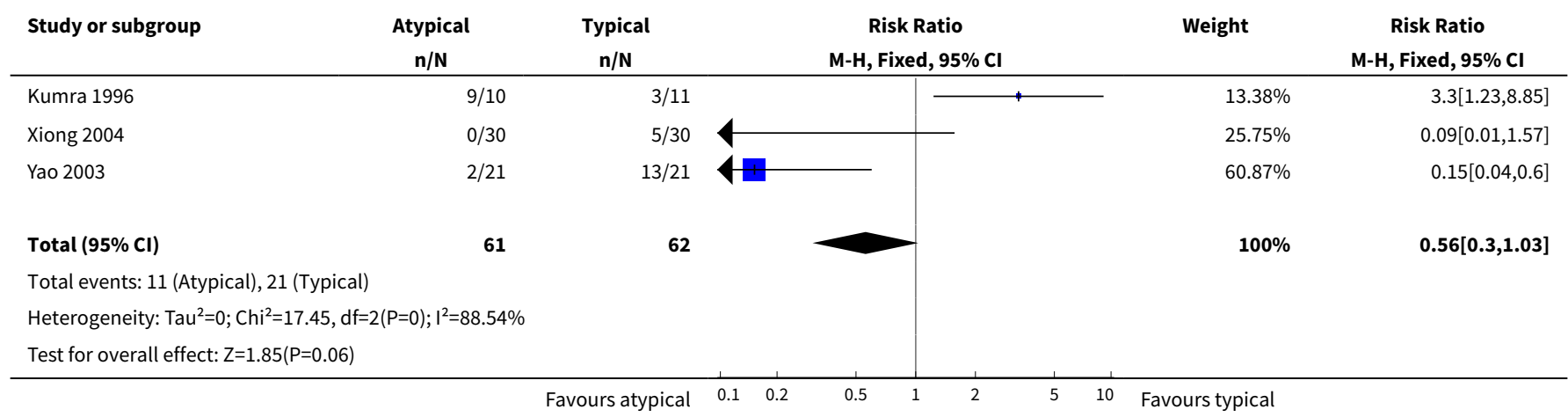

Analysis 1.12. Comparison 1 ATYPICAL vs TYPICAL ANTIPSYCHOTICS (only short term), Outcome 12 Adverse effects: 4. Anticholinergic adverse effects (TESS).

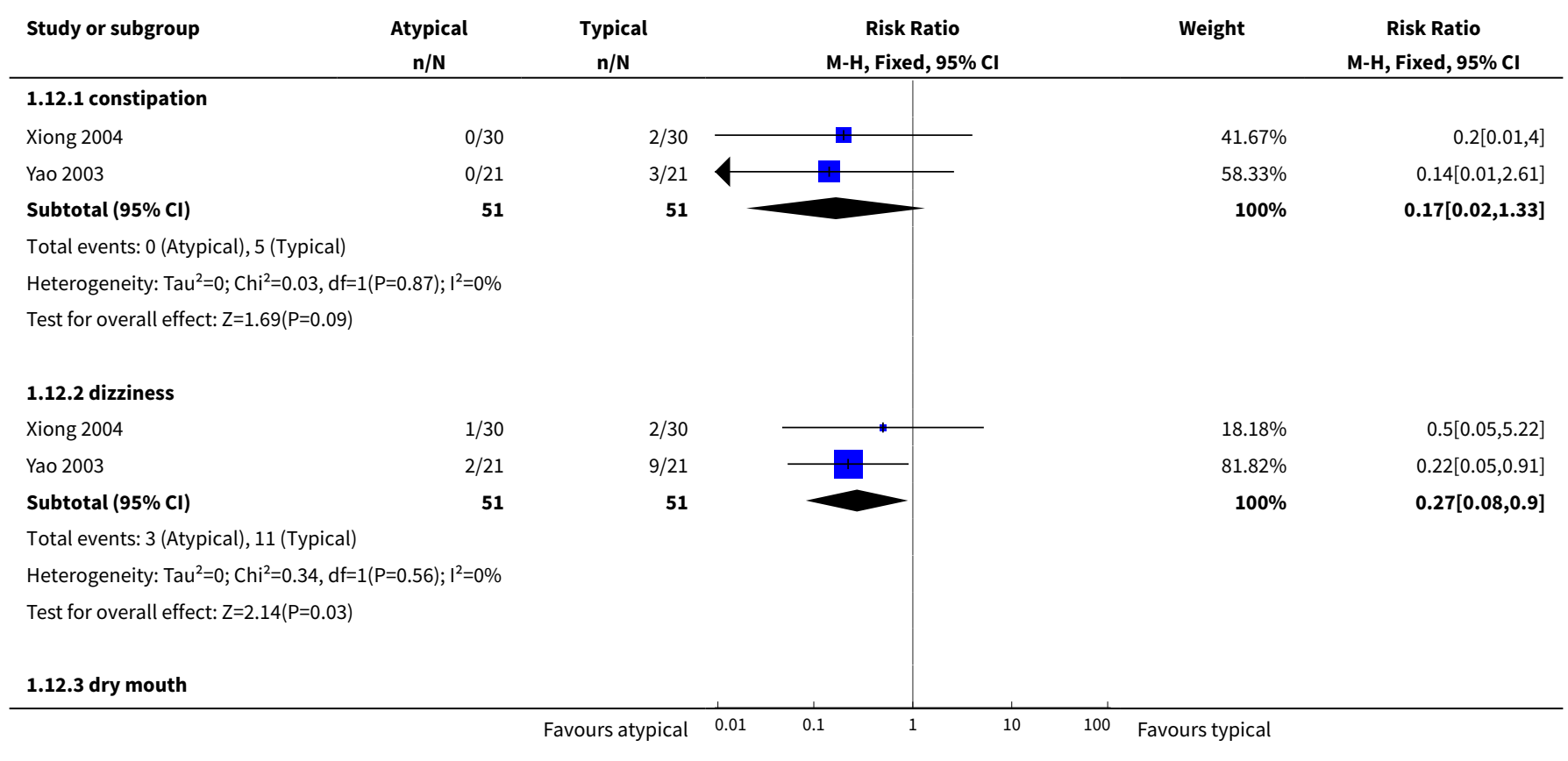




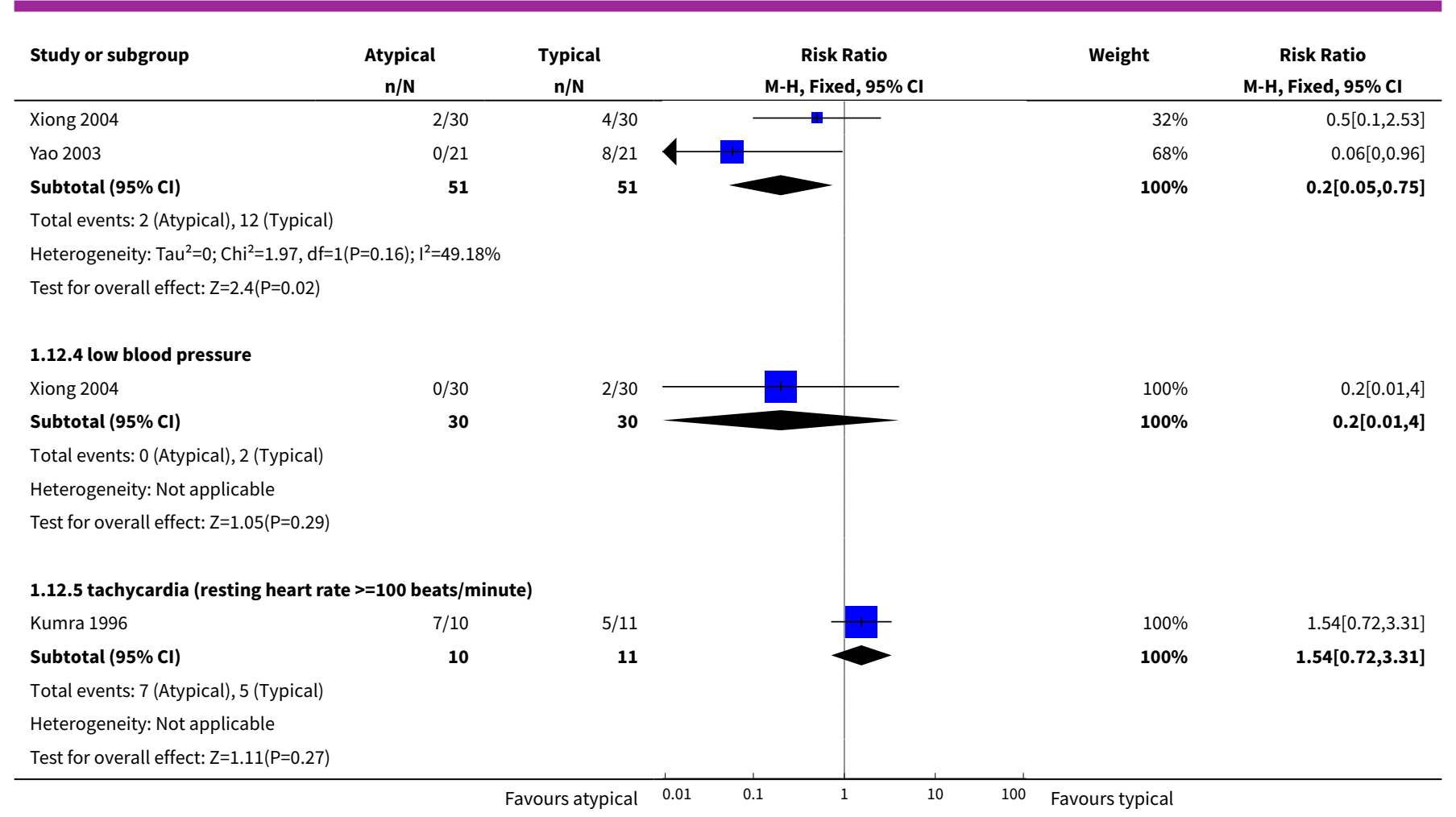

Analysis 1.13. Comparison 1 ATYPICAL vs TYPICAL ANTIPSYCHOTICS (only short term), Outcome 13 Adverse effects: 5. Hypersalivation (TESS).

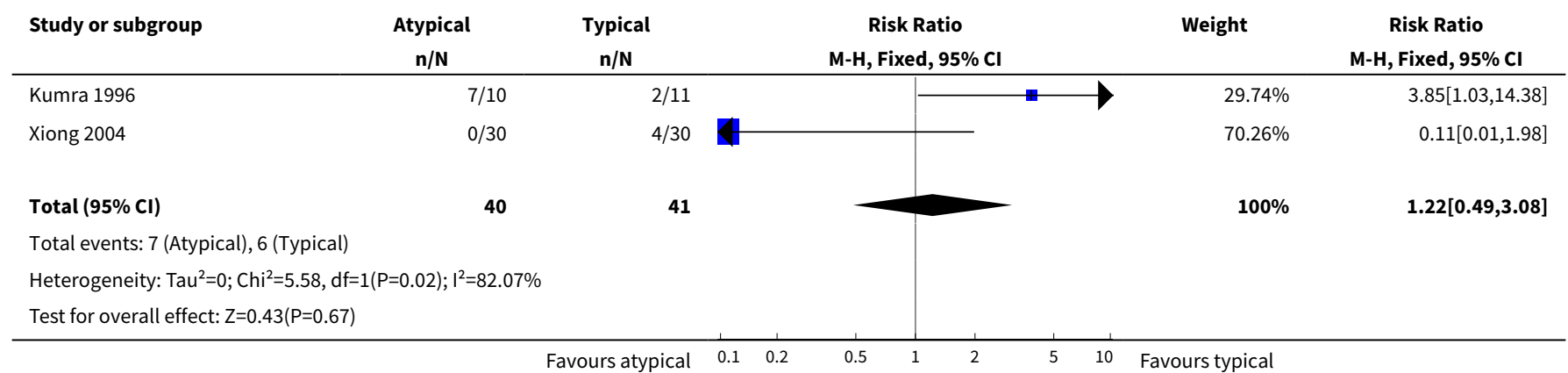

Analysis 1.14. Comparison 1 ATYPICAL vs TYPICAL ANTIPSYCHOTICS (only short term), Outcome 14 Adverse effects: 6 . Drop in the absolute neutrophil count below $1500 \mathrm{~mm}$ cube.

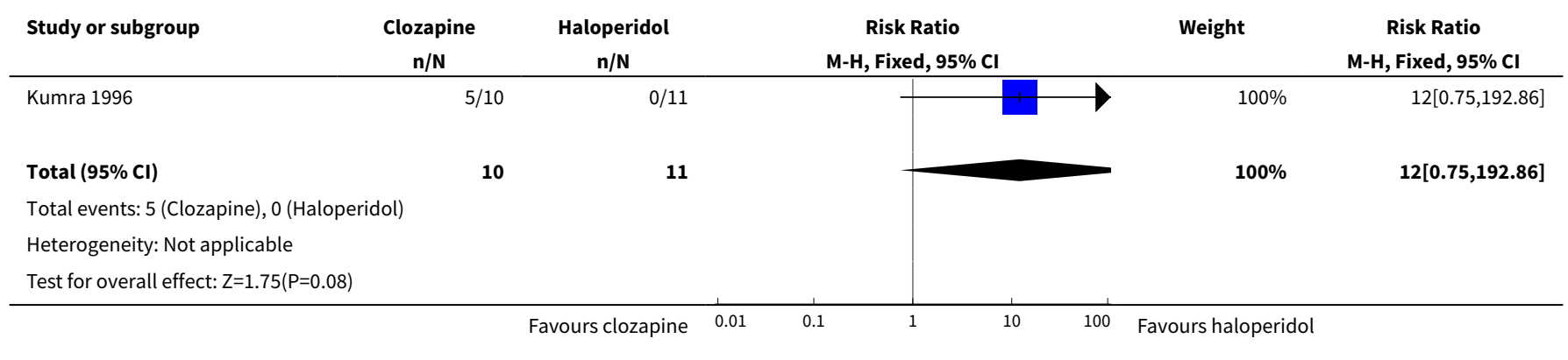


Analysis 1.15. Comparison 1 ATYPICAL vs TYPICAL ANTIPSYCHOTICS (only short term), Outcome 15 Adverse effects: 7. Seizure.

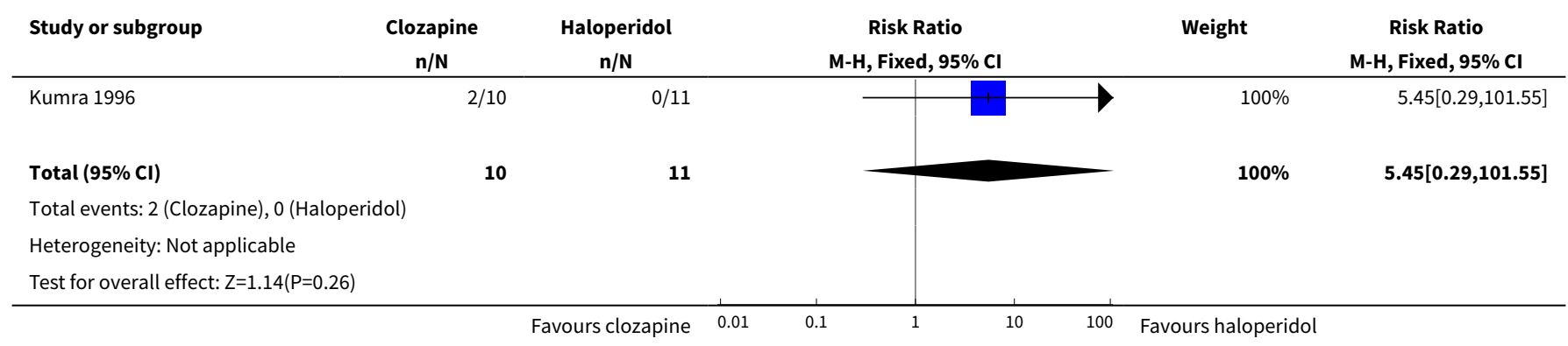

Analysis 1.16. Comparison 1 ATYPICAL vs TYPICAL ANTIPSYCHOTICS (only short term), Outcome 16 Leaving the study early: 1. Due to adverse effects.

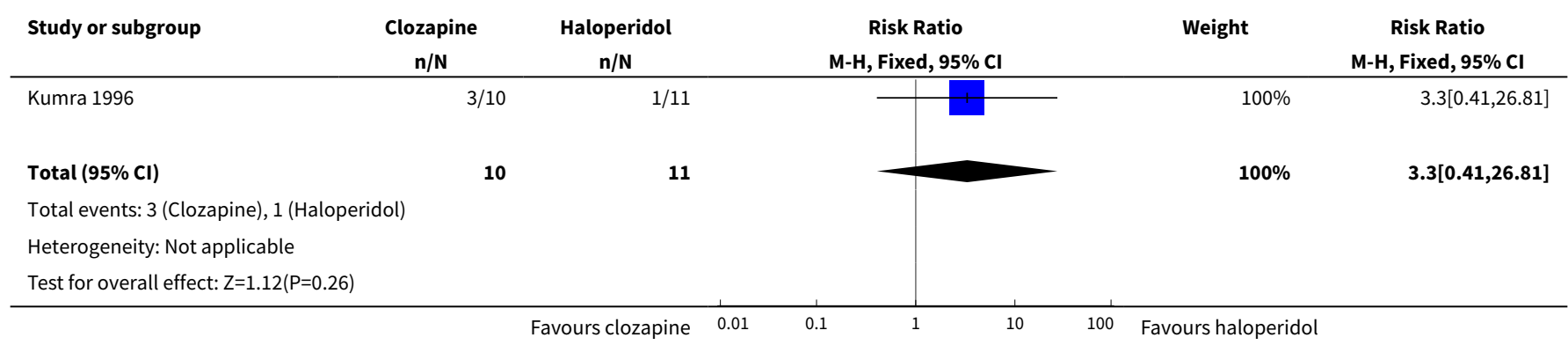

Analysis 1.17. Comparison 1 ATYPICAL vs TYPICAL ANTIPSYCHOTICS (only short term), Outcome 17 Leaving the study early: 2 . Due to neuroleptic malignant syndrome.

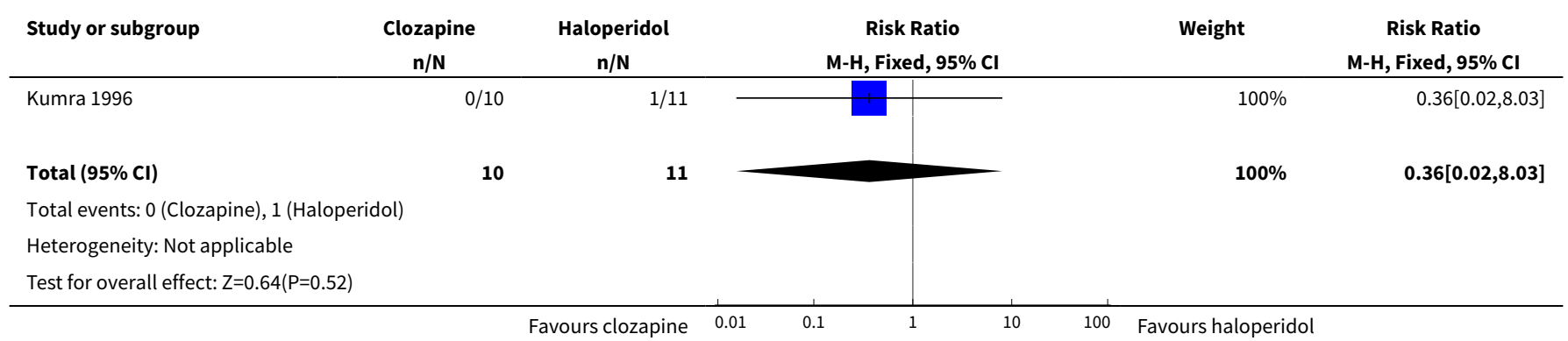

Analysis 1.18. Comparison 1 ATYPICAL vs TYPICAL ANTIPSYCHOTICS (only short term), Outcome 18 Leaving the study early: 3. Due to drop in neutrophil count.

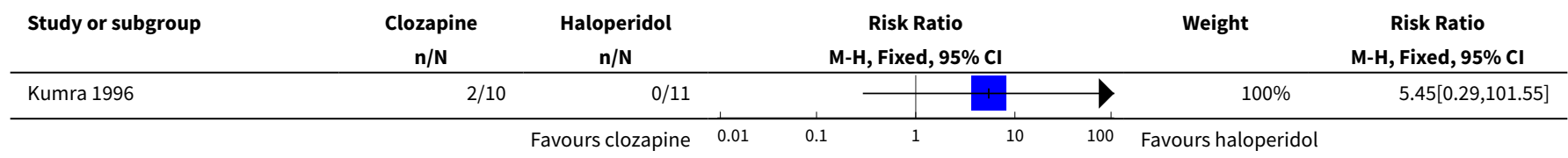




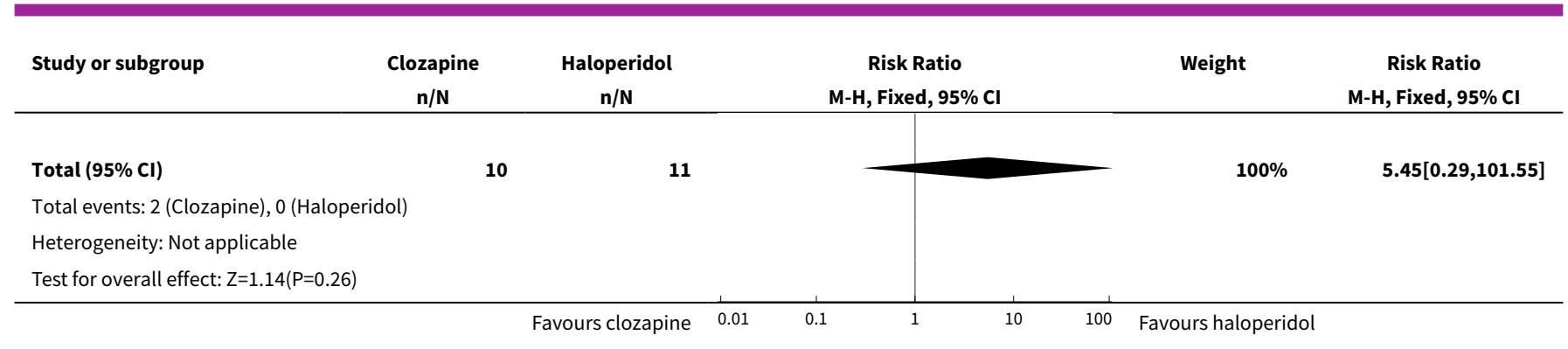

Comparison 2. ATYPICAL vs ATYPICAL ANTIPSYCHOTICS (only short term)

\begin{tabular}{|c|c|c|c|c|}
\hline Outcome or subgroup title & $\begin{array}{l}\text { No. of } \\
\text { studies }\end{array}$ & $\begin{array}{l}\text { No. of } \\
\text { partici- } \\
\text { pants }\end{array}$ & Statistical method & Effect size \\
\hline $\begin{array}{l}1 \text { Global state: } 1 . \text { Not showing any re- } \\
\text { sponse (CGI-S) }\end{array}$ & 1 & 25 & Risk Ratio (M-H, Fixed, 95\% Cl) & $1.35[0.47,3.89]$ \\
\hline $\begin{array}{l}2 \text { Global state: } 2 \text {. Worsening of symp- } \\
\text { toms (CGI-S) }\end{array}$ & 1 & 25 & Risk Ratio (M-H, Fixed, 95\% Cl) & $0.22[0.01,4.08]$ \\
\hline $\begin{array}{l}3 \text { Adverse effects: } 1 \text {. Anticholinergic } \\
\text { adverse effects }\end{array}$ & 1 & & Risk Ratio (M-H, Fixed, 95\% Cl) & Subtotals only \\
\hline 3.1 constipation & 1 & 25 & Risk Ratio (M-H, Fixed, 95\% Cl) & $1.08[0.18,6.53]$ \\
\hline 3.2 ECG anomalies & 1 & 25 & Risk Ratio (M-H, Fixed, 95\% Cl) & $2.17[0.22,20.94]$ \\
\hline $\begin{array}{l}3.3 \text { tachycardia (>100 beats/minute } \\
\text { supine) }\end{array}$ & 1 & 25 & Risk Ratio (M-H, Fixed, 95\% Cl) & $3.25[1.14,9.24]$ \\
\hline 4 Adverse effects: 2 . Hypersalivation & 1 & 25 & Risk Ratio (M-H, Fixed, 95\% Cl) & $2.17[0.87,5.37]$ \\
\hline $\begin{array}{l}5 \text { Adverse effects: } 4 \text {. Difficulty concen- } \\
\text { trating }\end{array}$ & 1 & 25 & Risk Ratio (M-H, Fixed, 95\% Cl) & $4.33[0.56,33.53]$ \\
\hline 6 Adverse effects: 5. Somnolence & 1 & 25 & Risk Ratio (M-H, Fixed, 95\% Cl) & $1.08[0.18,6.53]$ \\
\hline 7 Adverse effects: 7 . Hypertension & 1 & 25 & Risk Ratio (M-H, Fixed, 95\% Cl) & $2.89[0.99,8.42]$ \\
\hline 8 Adverse effects: 1 . Enuresis & 1 & 25 & Risk Ratio (M-H, Fixed, 95\% Cl) & $5.42[0.73,39.97]$ \\
\hline $\begin{array}{l}9 \text { Adverse effects: } 10 \text {. Drop in ab- } \\
\text { solute neutrophil count below } 1500 \\
\text { cells/microlitre }\end{array}$ & 1 & 25 & Risk Ratio (M-H, Fixed, 95\% Cl) & $2.17[0.22,20.94]$ \\
\hline $\begin{array}{l}10 \text { Leaving the study early - due to } \\
\text { rapid deterioration in mental state }\end{array}$ & 1 & 25 & Risk Ratio (M-H, Fixed, 95\% Cl) & $0.36[0.02,8.05]$ \\
\hline
\end{tabular}


Analysis 2.1. Comparison 2 ATYPICAL vs ATYPICAL ANTIPSYCHOTICS (only short term), Outcome 1 Global state: 1 . Not showing any response (CGI-S).

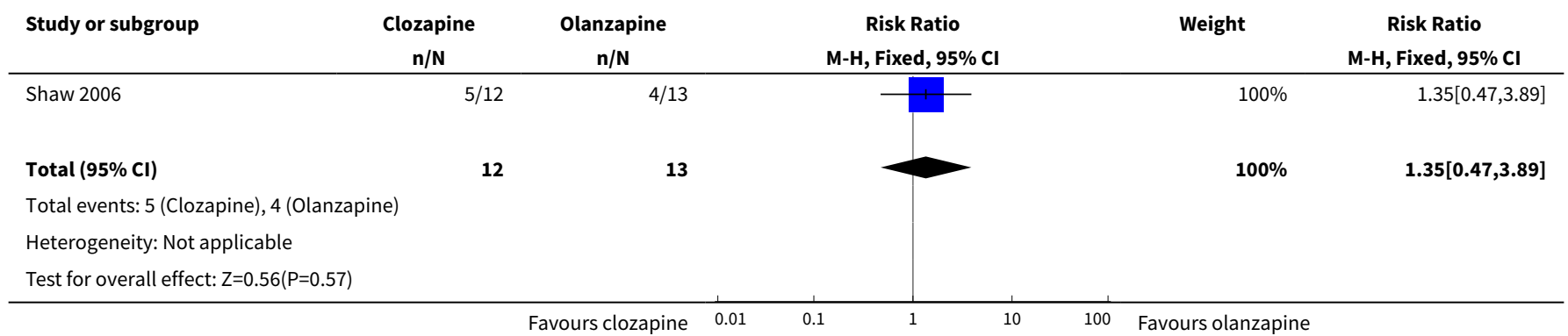

Analysis 2.2. Comparison 2 ATYPICAL vs ATYPICAL ANTIPSYCHOTICS (only short term), Outcome 2 Global state: 2 . Worsening of symptoms (CGI-S).

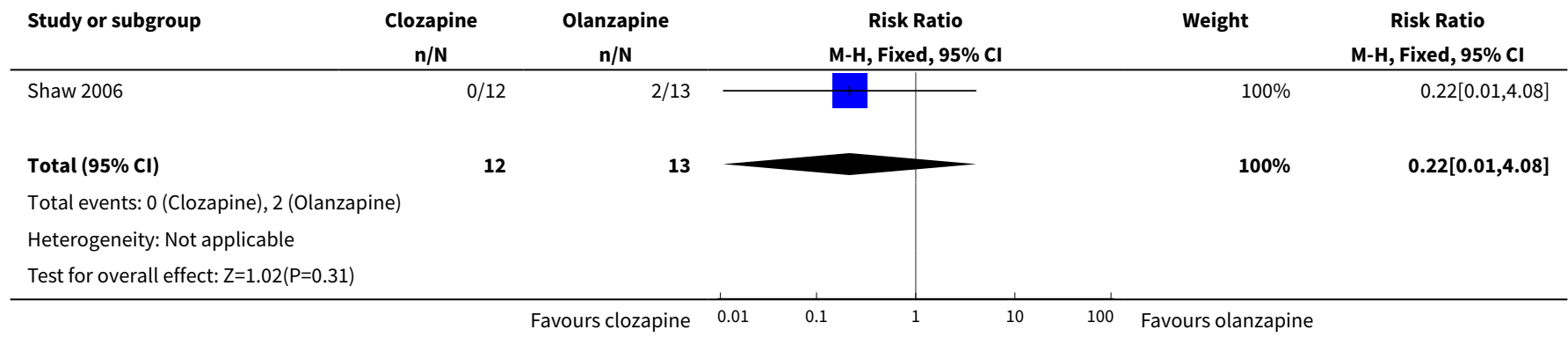

Analysis 2.3. Comparison 2 ATYPICAL vs ATYPICAL ANTIPSYCHOTICS (only short term), Outcome 3 Adverse effects: 1 . Anticholinergic adverse effects.

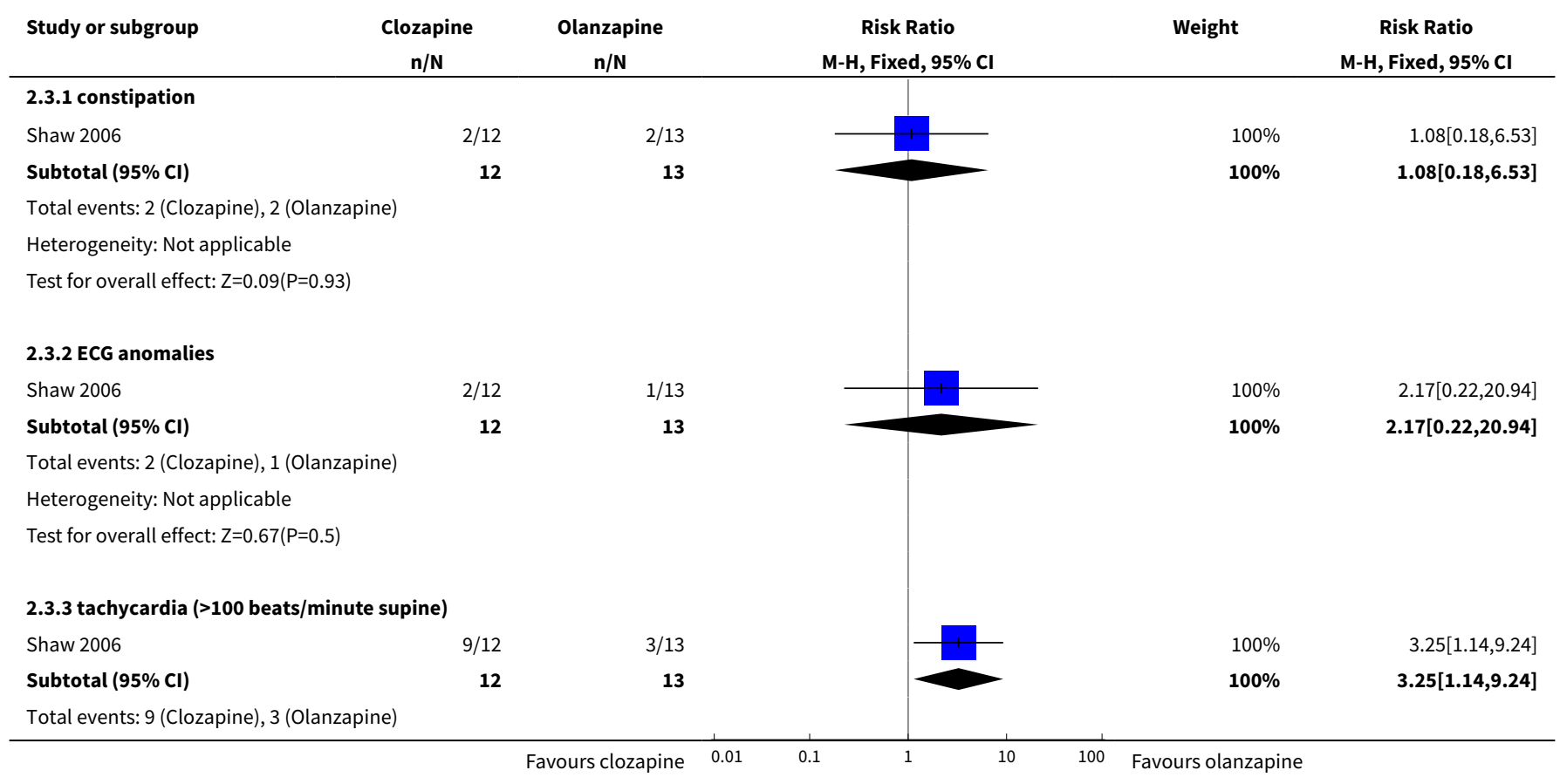




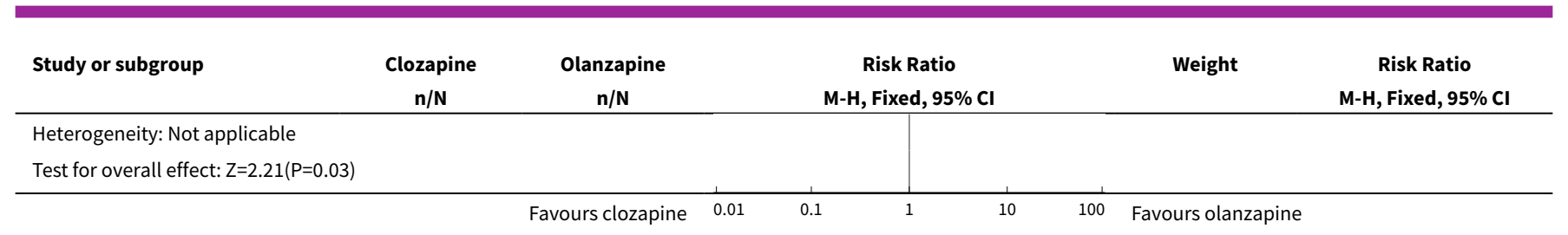

Analysis 2.4. Comparison 2 ATYPICAL vs ATYPICAL ANTIPSYCHOTICS (only short term), Outcome 4 Adverse effects: 2 . Hypersalivation.

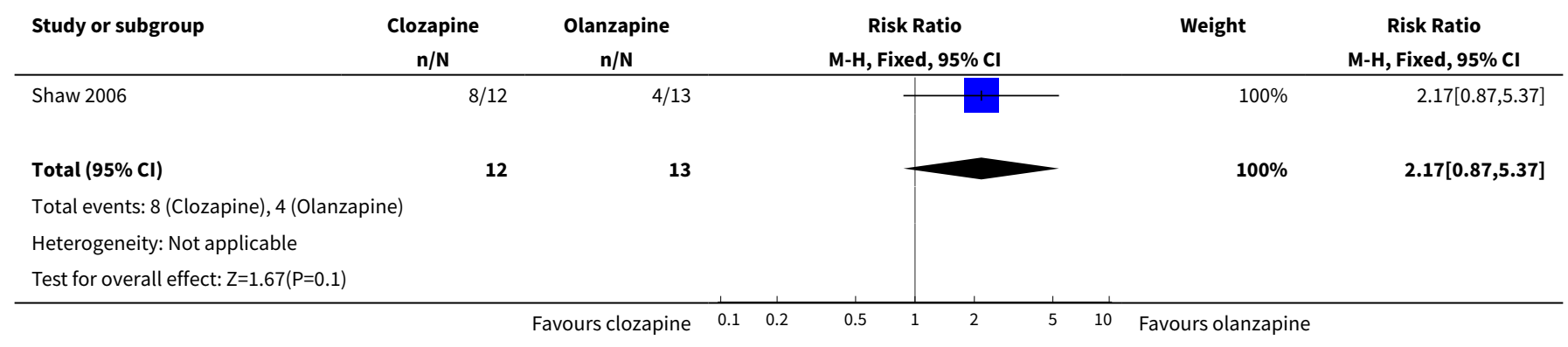

Analysis 2.5. Comparison 2 ATYPICAL vs ATYPICAL ANTIPSYCHOTICS (only short term), Outcome 5 Adverse effects: 4. Difficulty concentrating.

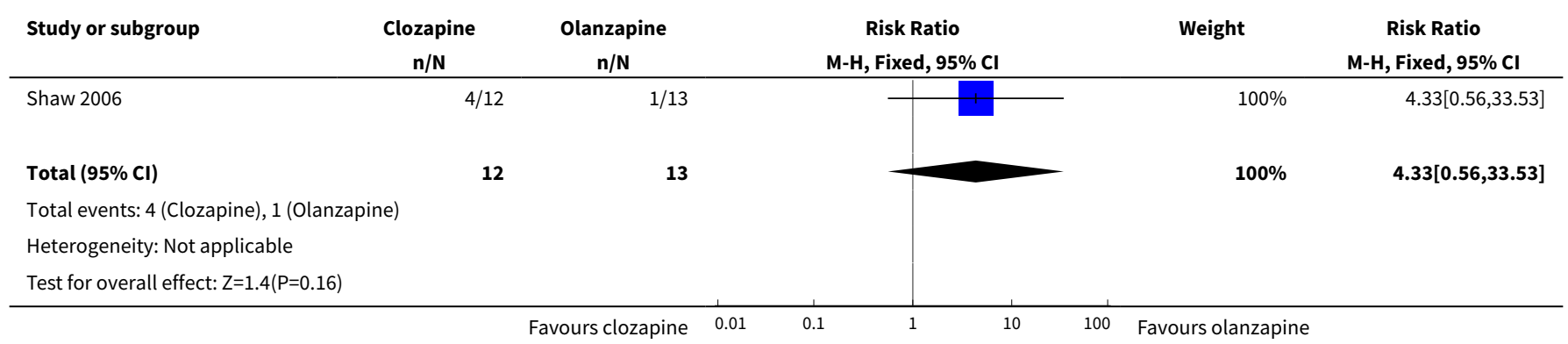

Analysis 2.6. Comparison 2 ATYPICAL vs ATYPICAL ANTIPSYCHOTICS (only short term), Outcome 6 Adverse effects: 5. Somnolence.

\begin{tabular}{|c|c|c|c|c|c|}
\hline Study or subgroup & $\begin{array}{c}\text { Clozapine } \\
\mathrm{n} / \mathrm{N}\end{array}$ & $\begin{array}{c}\text { Olanzapine } \\
n / N\end{array}$ & $\begin{array}{c}\text { Risk Ratio } \\
\text { M-H, Fixed, 95\% Cl }\end{array}$ & Weight & $\begin{array}{c}\text { Risk Ratio } \\
\text { M-H, Fixed, 95\% Cl }\end{array}$ \\
\hline Shaw 2006 & $2 / 12$ & $2 / 13$ & $\overline{1}$ & $100 \%$ & $1.08[0.18,6.53]$ \\
\hline Total $(95 \% \mathrm{Cl})$ & 12 & 13 & & $100 \%$ & $1.08[0.18,6.53]$ \\
\hline \multicolumn{6}{|c|}{ Total events: 2 (Clozapine), 2 (Olanzapine) } \\
\hline \multicolumn{6}{|c|}{ Heterogeneity: Not applicable } \\
\hline Test for overall effec & & & & & \\
\hline
\end{tabular}


Analysis 2.7. Comparison 2 ATYPICAL vs ATYPICAL ANTIPSYCHOTICS (only short term), Outcome 7 Adverse effects: 7 . Hypertension.

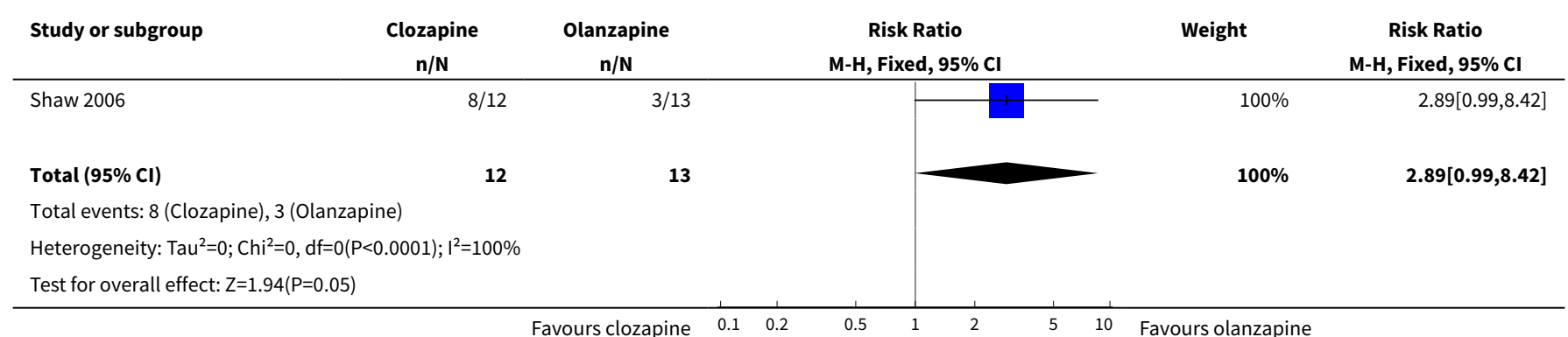

Analysis 2.8. Comparison 2 ATYPICAL vs ATYPICAL ANTIPSYCHOTICS (only short term), Outcome 8 Adverse effects: 1 . Enuresis.

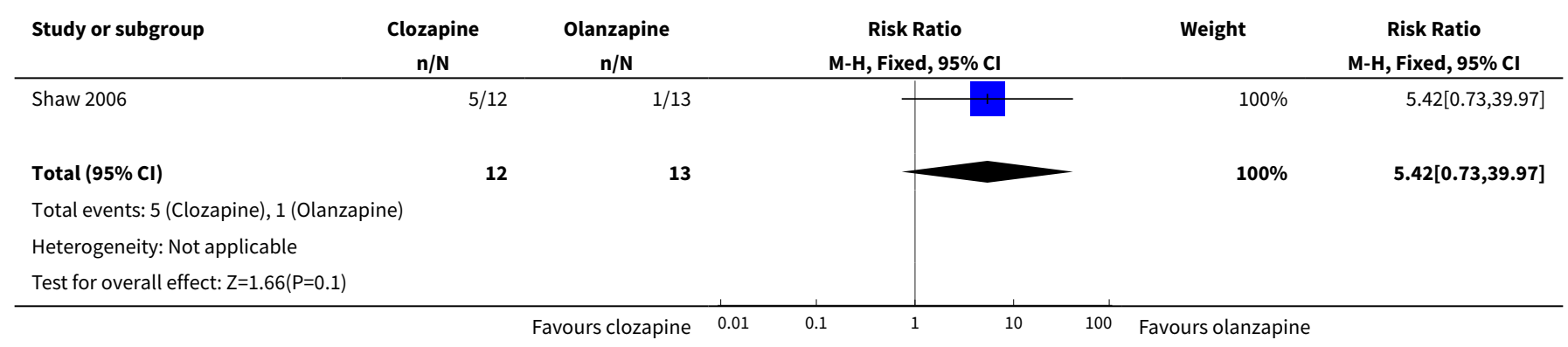

Analysis 2.9. Comparison 2 ATYPICAL vs ATYPICAL ANTIPSYCHOTICS (only short term), Outcome 9 Adverse effects: 10. Drop in absolute neutrophil count below 1500 cells/microlitre.

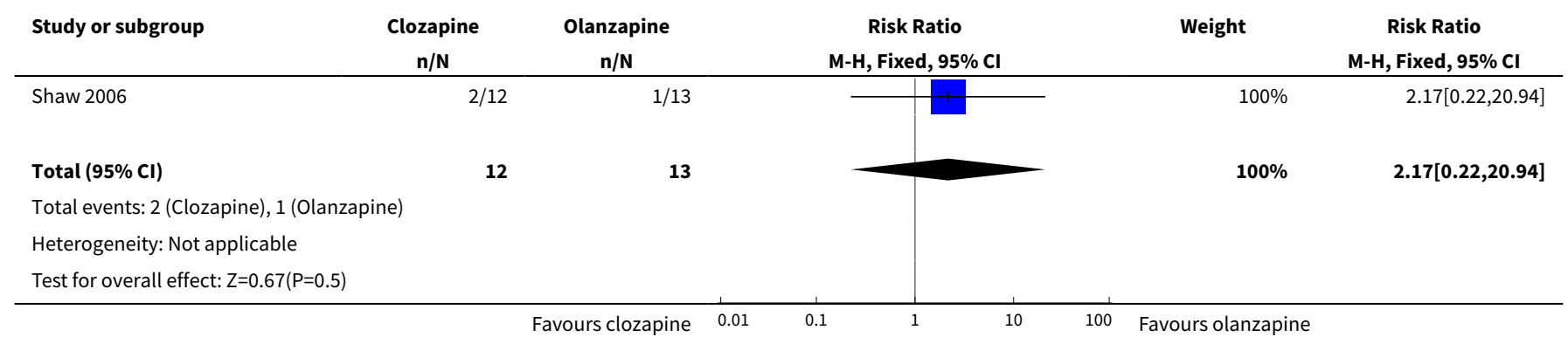

Analysis 2.10. Comparison 2 ATYPICAL vs ATYPICAL ANTIPSYCHOTICS (only short term), Outcome 10 Leaving the study early - due to rapid deterioration in mental state.

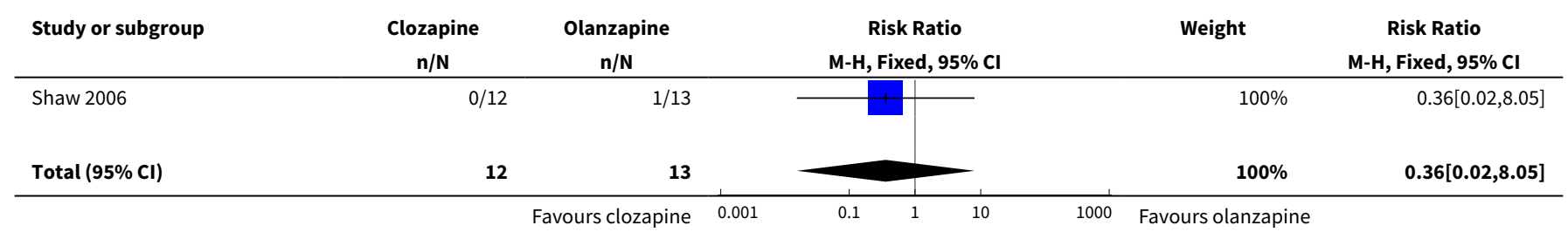




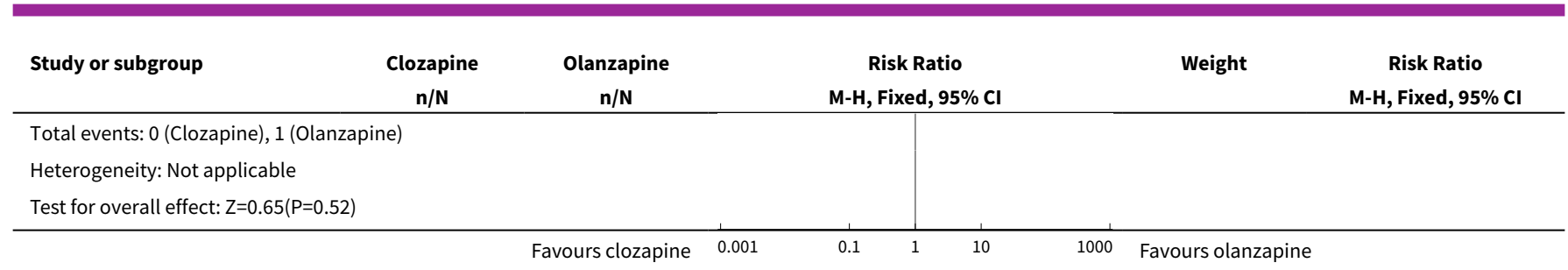

\section{Comparison 3. TYPICAL vs TYPICAL ANTIPSYCHOTICS (only short term)}

\begin{tabular}{lllll}
\hline Outcome or subgroup title & $\begin{array}{l}\text { No. of } \\
\text { studies }\end{array}$ & $\begin{array}{l}\text { No. of } \\
\text { partici- } \\
\text { pants }\end{array}$ & Statistical method & Effect size \\
\hline $\begin{array}{l}1 \text { Global state: Unchanged or } \\
\text { worse (CGI) }\end{array}$ & 1 & & Risk Ratio (M-H, Fixed, 95\% Cl) & Subtotals only \\
\hline $\begin{array}{l}1.1 \text { Anxiety } \\
1.2 \text { Regressive behaviour }\end{array}$ & 1 & 60 & Risk Ratio (M-H, Fixed, 95\% Cl) & $0.86[0.48,1.53]$ \\
\hline $\begin{array}{l}2 \text { Adverse effects: 1. All adverse ef- } \\
\text { fects (TESS) }\end{array}$ & 1 & 60 & Risk Ratio (M-H, Fixed, 95\% Cl) & $0.92[0.69,1.21]$ \\
\hline $\begin{array}{l}\text { 3 Adverse effects: 2. Extrapyrami- } \\
\text { dal adverse effects (TESS) }\end{array}$ & 2 & 30 & Risk Ratio (M-H, Fixed, 95\% Cl) & $1.13[0.60,2.11]$ \\
\hline $\begin{array}{l}4 \text { Adverse effects: } 3 \text {. Weight gain } \\
\text { (TESS) }\end{array}$ & 1 & 90 & Risk Ratio (M-H, Fixed, 95\% Cl) & $1.2[0.58,2.46]$ \\
\hline
\end{tabular}

Analysis 3.1. Comparison 3 TYPICAL vs TYPICAL ANTIPSYCHOTICS (only short term), Outcome $1 \mathrm{Global}$ state: Unchanged or worse (CGI).

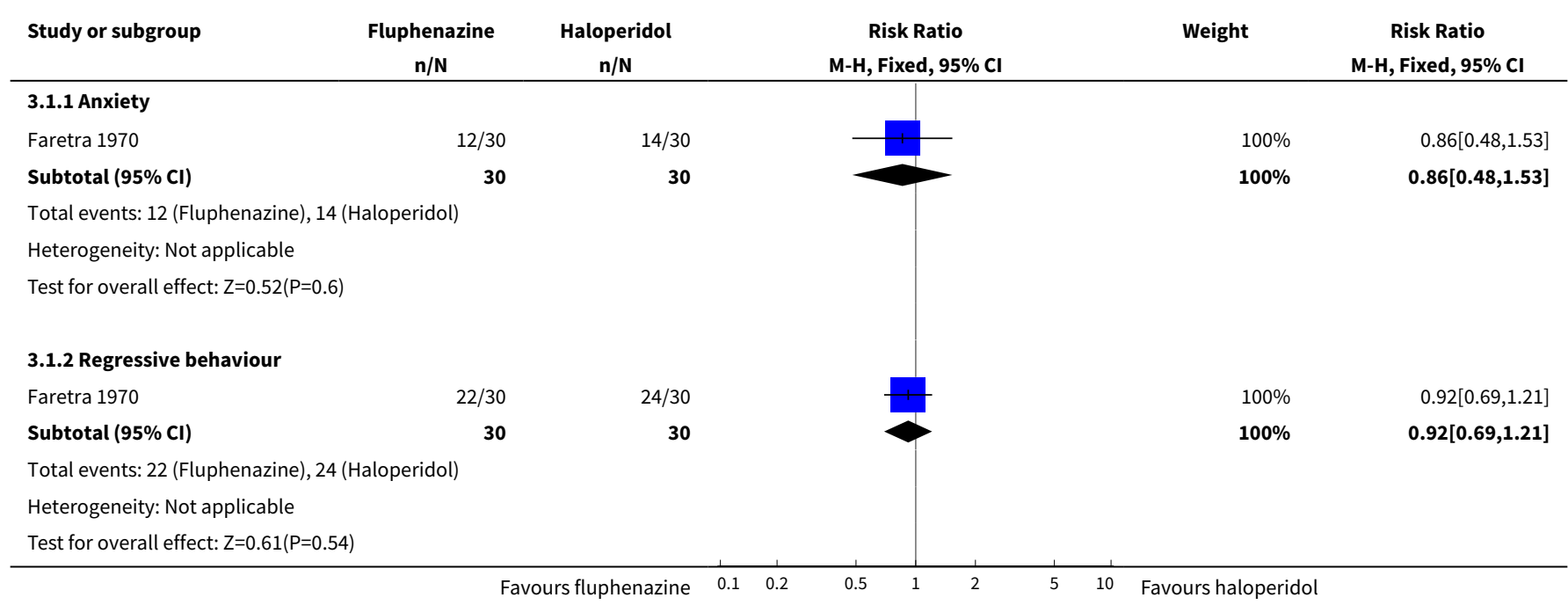


Analysis 3.2. Comparison 3 TYPICAL vs TYPICAL ANTIPSYCHOTICS (only short term), Outcome 2 Adverse effects: 1 . All adverse effects (TESS).

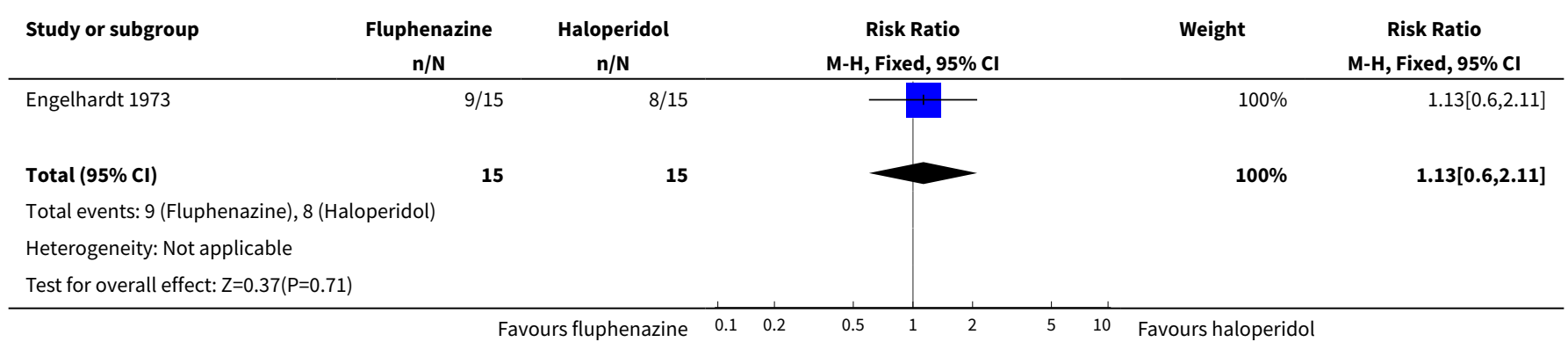

Analysis 3.3. Comparison 3 TYPICAL vs TYPICAL ANTIPSYCHOTICS (only short term), Outcome 3 Adverse effects: 2. Extrapyramidal adverse effects (TESS).

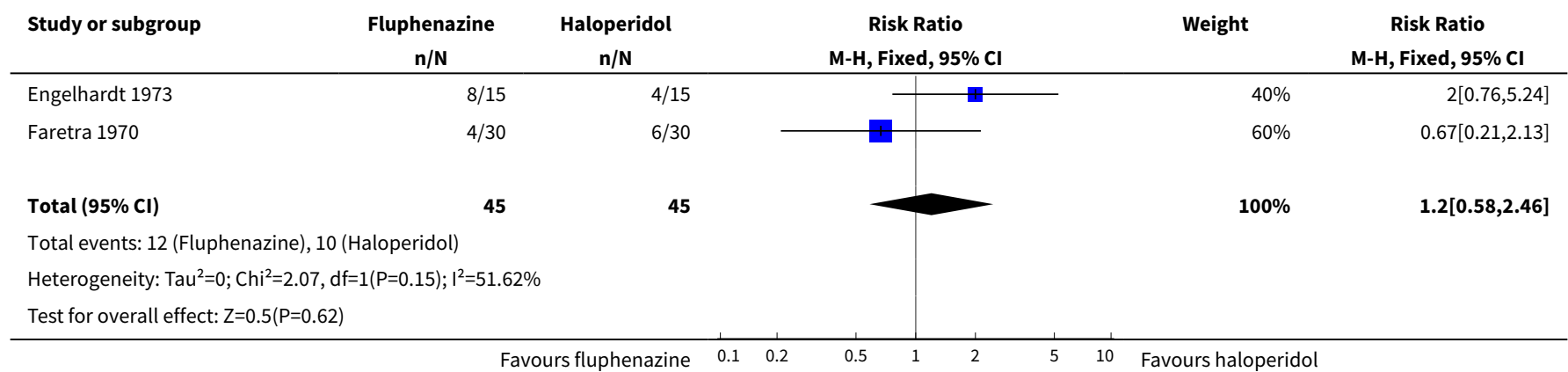

Analysis 3.4. Comparison 3 TYPICAL vs TYPICAL ANTIPSYCHOTICS (only short term), Outcome 4 Adverse effects: 3. Weight gain (TESS).

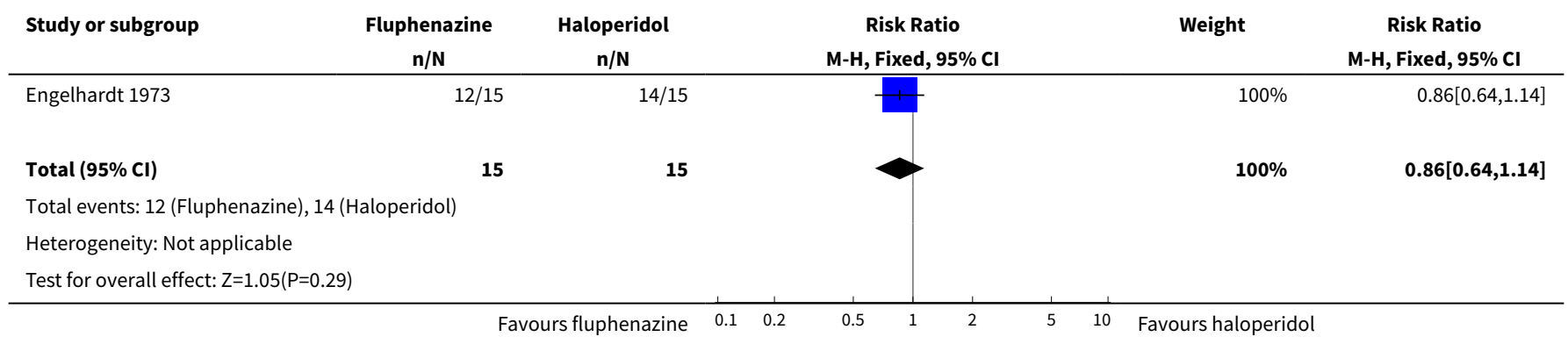

\section{ADDITIONAL TABLES}

Table 1. Suggested design of study

\begin{tabular}{lll}
\hline $\begin{array}{l}\text { Type of } \\
\text { study }\end{array}$ & Patients & $\begin{array}{l}\text { Interven- Outcomes } \\
\text { tions }\end{array}$ \\
\hline
\end{tabular}


Table 1. Suggested design of study (Continued)

\begin{tabular}{|c|c|c|c|c|}
\hline $\begin{array}{l}\text { Allocation: } \\
\text { random } \\
\text { Blinding: } \\
\text { blind or in- } \\
\text { dependent } \\
\text { raters. } \\
\text { Duration: } \\
\text { minimum } \\
\text { one year } \\
\text { follow-up }\end{array}$ & $\begin{array}{l}\text { Diagnosis: Children } \\
\text { with a diagnosis of } \\
\text { schizophrenia accord- } \\
\text { ing to standard diag- } \\
\text { nostic criteria. } \\
\text { Age: under } 13 \text { years } \\
\text { old at the time diagno- } \\
\text { sis. } \\
\text { Sex: male and female. } \\
\mathrm{N}=30 .^{*}\end{array}$ & $\begin{array}{l}\text { 1. Typical } \\
\text { or 'conven- } \\
\text { tional' an- } \\
\text { tipsychotic } \\
\text { drugs. } \\
\text { 2. Atyp- } \\
\text { ical an- } \\
\text { tipsychotic } \\
\text { drugs }\end{array}$ & 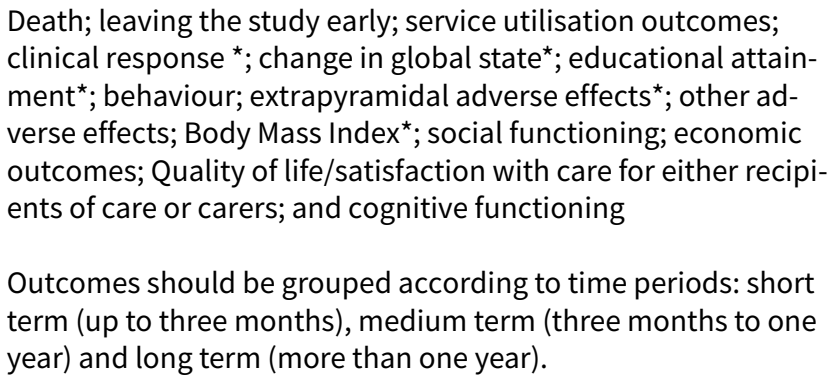 & $\begin{array}{l}{ }^{\star} \text { Denotes } \\
\text { primary } \\
\text { outcomes } \\
\text { of inter- } \\
\text { est. }\end{array}$ \\
\hline & & 3. & & \\
\hline
\end{tabular}

WHAT'S NEW

\begin{tabular}{lll}
\hline Date & Event & Description \\
\hline 26 April 2012 & Amended & Additional table linked to text. \\
\hline
\end{tabular}

\section{H I S T O R Y}

Protocol first published: Issue 1, 2003

Review first published: Issue 3, 2007

\begin{tabular}{lll}
\hline Date & Event & Description \\
\hline 17 September 2008 & Amended & Minor edit to references. \\
\hline 17 September 2008 & Amended & Converted to new review format. \\
\hline
\end{tabular}

\section{CONTRIBUTIONS OF AUTHORS}

Eilis Kennedy - Project initiation, protocol writing, data extraction, data analysis, manuscript writing.

Ajit Kumar - Protocol modification, data extraction, data analysis, writing the first draft of the manuscript and coordinating the review team. Soumitra Datta - Protocol modification, data extraction, data analysis, writing the first draft of the manuscript.

\section{DECLARATIONSOF INTEREST}

Eilis Kennedy - None known

Ajit Kumar - None known

Soumitra Shankar Datta - None known

\section{SOURCES OF SUPPORT}

\section{Internal sources}

- The Tavistock Clinic/University College London, UK.

\section{External sources}

- Yorkshire Deanery and North West Deanery, UK. 
INDEX TERMS

\section{Medical Subject Headings (MeSH)}

Age of Onset; Antipsychotic Agents [*therapeutic use]; Randomized Controlled Trials as Topic; Schizophrenia [ ${ }^{\star}$ drug therapy]

\section{MeSH check words}

Child; Humans 